\title{
Next Generation Nuclear Plant Project 2009 Status Report
}

May 2010

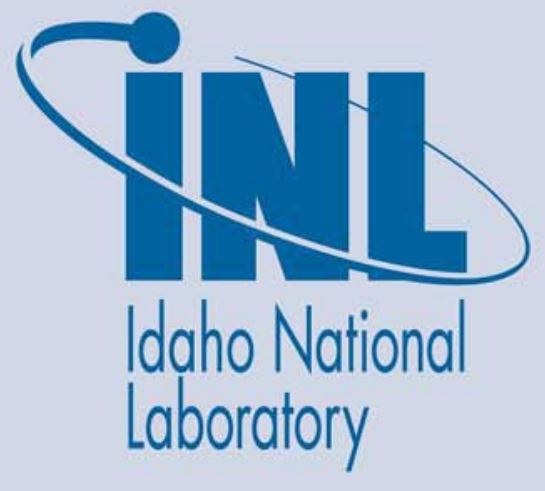

The INL is a U.S. Department of Energy National Laboratory operated by Battelle Energy Alliance 
INL/EXT-09-17505

\title{
Next Generation Nuclear Plant Project 2009 Status Report
}

May 2010

\author{
Idaho National Laboratory \\ Next Generation Nuclear Plant Project \\ Idaho Falls, Idaho 83415
}

http://www.inl.gov

Prepared for the

U.S. Department of Energy

Office of Nuclear Energy

Under DOE Idaho Operations Office

Contract DE-AC07-05ID14517 
INL/EXT-09-17505

Revision 0 


\section{Executive Summary}

The Next Generation Nuclear Plant (NGNP) Project was established based on a Department of Energy (DOE) Generation IV Research and Development (R\&D) evaluation completed in 2003 to integrate high-temperature reactor technology with advanced hydrogen, electricity, and process heat production capabilities. The project was authorized via the Energy Policy Act of 2005 (EPAct). The mission of the NGNP Project is to broaden the environmental and economic benefits of nuclear energy technology to the United States and other economies by demonstrating its applicability to market sectors not served by light water reactors (LWRs). Those markets typically use fossil fuels to fulfill their energy needs, and high temperature gas-cooled reactors (HTGRs) can be used in place of fossil fuels, reducing or eliminating the greenhouse gas emissions from these fuels. The use of HTGRs also provides a more secure energy source and insulates the end user from the economic problems associated with the volatility in the price of fossil fuels. The benefits of accomplishing these mission objectives are displayed in the figure below.

Significant accomplishments have been realized in the areas of $R \& D$, engineering, and licensing since the project's inception. Those accomplishments include:

\section{$R \& D$}

- Irradiation-tested robust, low-defect fuel (laboratory manufactured) with no detected failures and an increased energy utilization, nearly twice that of previous records. This provides the necessary basis for licensing the HTGR technology for co-location with industrial applications

- Developed fuel fabrication capability to manufacture the same low-defect fuel at an industrial scale (this fuel will be irradiated in 2010)

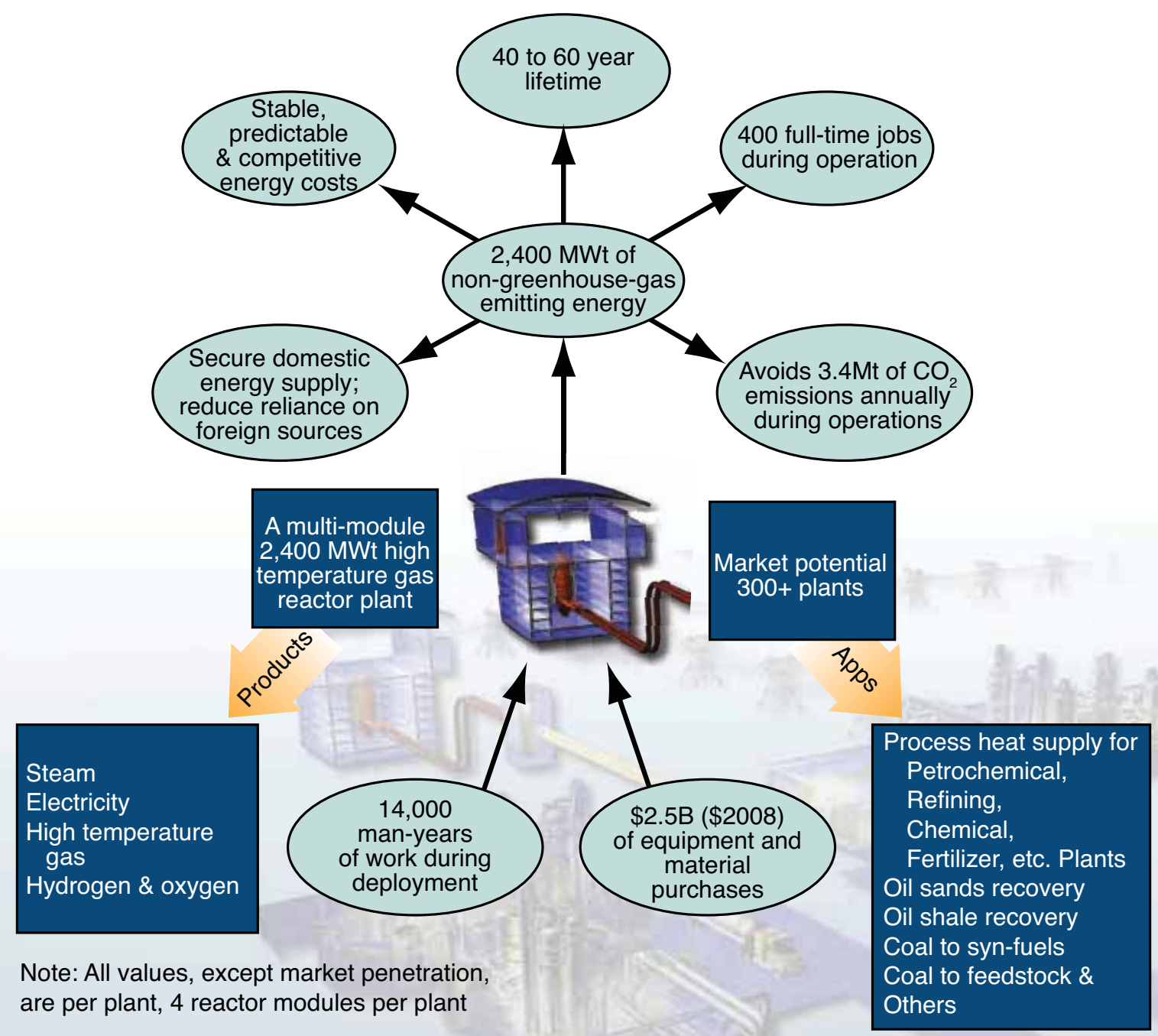


- Initiated state-of-the art graphite irradiation testing (graphite is the main reactor core structural material) to improve understanding of structural and neutronic behavior of the graphite during operations. The test includes several graphite samples and is designed to apply physical stress loading to simulate conditions similar to those expected in the reactor core

- Developed new methods for high temperature metals testing to allow for examination, characterization, and selection of heat transfer component materials of construction after testing at the temperatures, pressures, and environmental conditions similar to those that will be experienced in the reactor

- Initiated development and validation of analysis and modeling methods required to characterize the thermal, hydraulic, neutronic, and heat transfer conditions in the plant during normal and abnormal conditions

- Implemented, with Engineering, a tailored approach to technology risk measurement and management developed by the National Aeronautics and Space Administration and the Department of Defense, as recommended by the Government Accountability Office to reduce project cost and schedule risk.

\section{Engineering}

- Completed preconceptual designs for both pebble-bed and prismatic block reactors that provide a path forward for design

- Established, with industry, a mutual understanding of initial end-user needs and applications for an HTGR producing process heat as well as electricity. Used these needs to reduce some of the most challenging technology risks by identifying the operating conditions of the first-of-a-kind plant needed for the applications of interest

\section{Licensing}

- Developed a detailed licensing plan, laying out the activities needed to obtain a Combined License.

- Identified high-priority licensing issues to be worked early on with the NRC

- Initially developed priority white-papers and interacted with the NRC on these and other important policy topics to manage schedule uncertainties associated with licensing

- Obtained NRC agreement on the use of a content guide that will define the necessary inputs for the licensing application early in the process, thus improving the certainty of the process and helping all parties understand expectations.

While there remains both technical and policybased challenges to overcome, the NGNP has used its funding wisely to position for the future. The objectives outlined here-energy security, emissions reduction, and economic benefit - are more significant at this time in history than ever before. With continued federal support, continuity of funding, and appropriate involvement from industry, the project can successfully meet its mission.

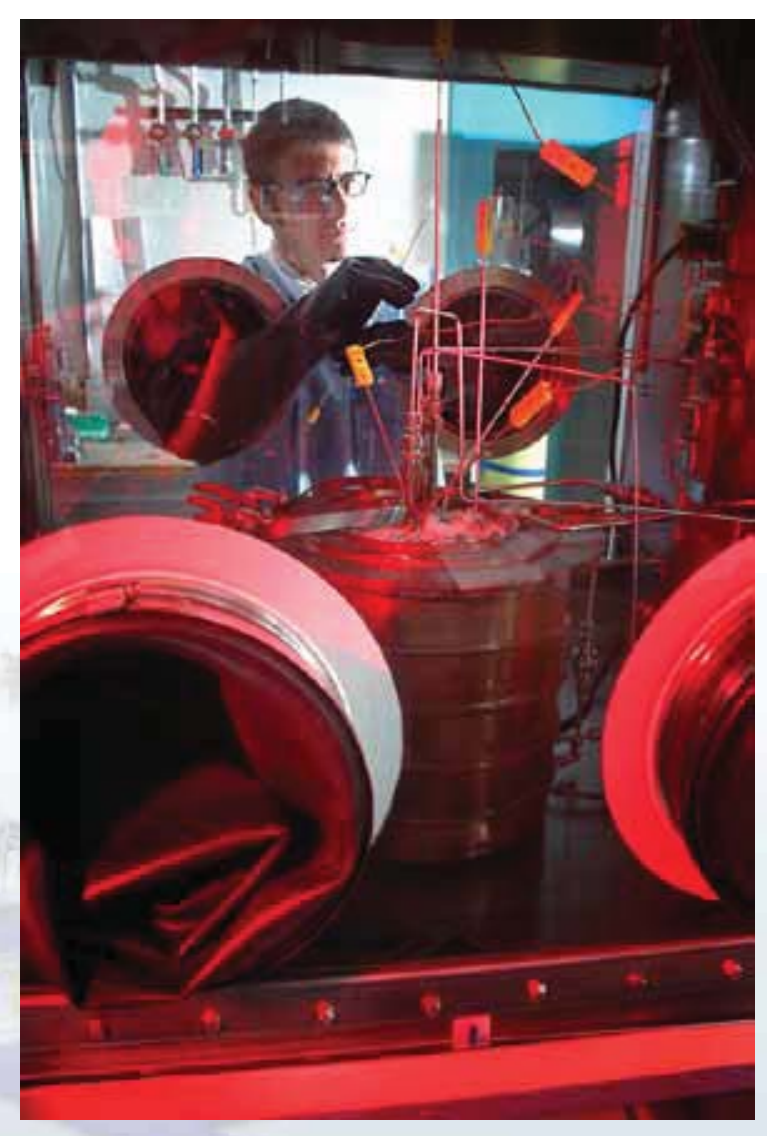


Purpose and Mission of Next Generation Nuclear Plant

Background of HTGRs

Project Accomplishments . .

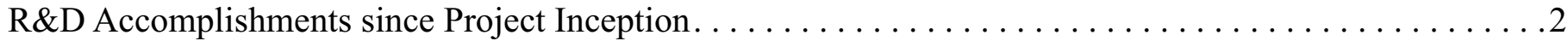

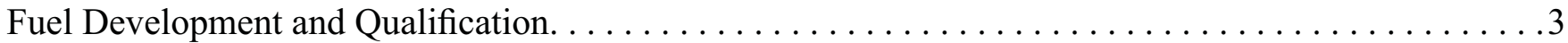

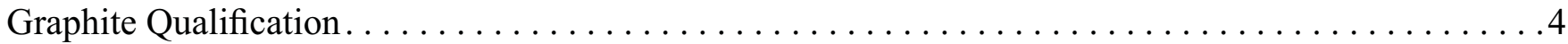

High Temperature Materials Qualification $\ldots \ldots \ldots \ldots \ldots \ldots \ldots \ldots \ldots \ldots \ldots \ldots \ldots \ldots \ldots \ldots \ldots \ldots \ldots$

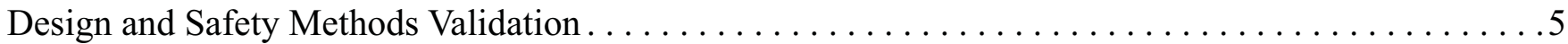

Technology Readiness. . . . . . . . . . . . . . . . . . . . . 6

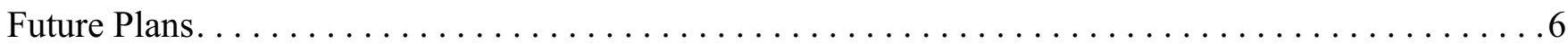

NGNP Engineering Accomplishments since Project Inception $\ldots \ldots \ldots \ldots \ldots \ldots \ldots \ldots \ldots \ldots \ldots \ldots \ldots$

NGNP Project Pre-conceptual Design $\ldots \ldots \ldots \ldots \ldots \ldots \ldots \ldots \ldots \ldots \ldots \ldots \ldots \ldots \ldots \ldots \ldots \ldots \ldots \ldots$

Nuclear System Supplier and Potential-End-User Input Defines the Scope of the Project . . . . . . . .6

Technical and Commercial Challenges Affecting Plant Deployment . . . . . . . . . . . . 8

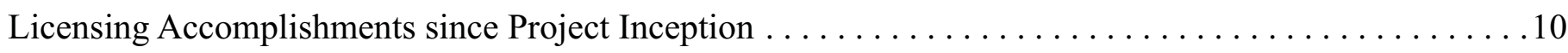

Identified Highest Priority Licensing Issues for Focused Interaction with NRC $\ldots \ldots \ldots \ldots \ldots$

Established Regular NGNP Project Interactions with NRC to Begin Issues Resolution . . . . . . . . 10

Commenced the Development of NGNP White Papers Addressing Priority Licensing Topics . . . . . . 10

Obtained Agreement on the Development of a COL Content Guide . . . . . . . . . . . . 11

Updates to NGNP Licensing Strategy (August 2008 Report to Congress) . . . . . . . . . . . . . . 11

Report to Congress - Summary of Recommended Licensing Approach . . . . . . . . . . . . . 11

Discussion of NGNP Project Implementation Consistent with the Recommended Approach . . . . . . . . 12

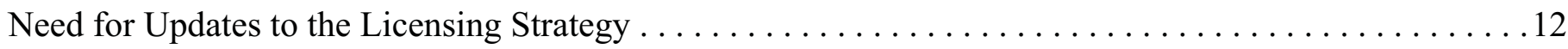

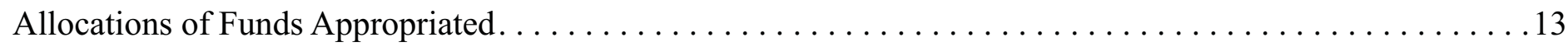

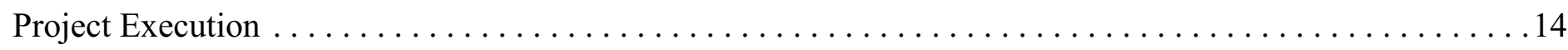

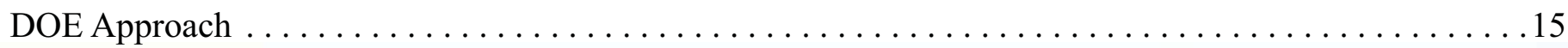

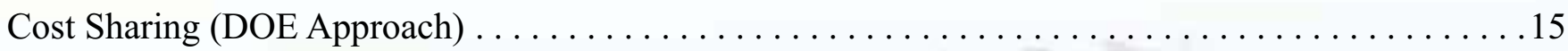

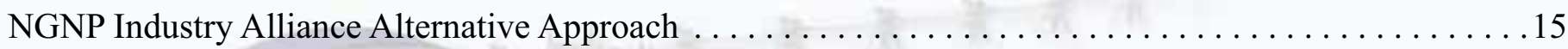

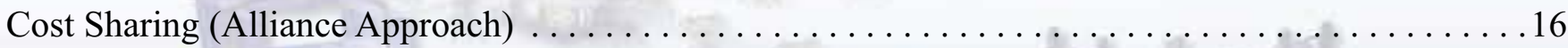

Conclusion 


\section{Next Generation Nuclear Plant Project 2009 Status Report}

\section{Purpose and Mission of Next Generation Nuclear Plant}

The Next Generation Nuclear Plant (NGNP) Project was established based on a Department of Energy (DOE) Generation IV Research and Development (R\&D) evaluation completed in 2003 to integrate high-temperature reactor technology with advanced hydrogen, electricity, and process heat production capabilities. The project was authorized via the Energy Policy Act of 2005 (EPAct). At its inception, the NGNP was anticipated to fuel the hydrogen economy, giving the United States an advanced energy solution that would reduce its carbon emissions and dependence on foreign fossil fuels. Although these purposes are still valid, the work accomplished by the project thus far, coupled with global changes in the energy sector, have revealed even more compelling and urgent reasons to proceed with development of the NGNP.

The mission of the NGNP Project is to broaden the environmental and economic benefits of nuclear energy technology to the United States and other economies by demonstrating its applicability to market sectors not served by light water reactors (LWRs). Those markets typically use fossil fuels to fulfill their energy needs, and high temperature gas-cooled reactors (HTGRs) can be used in place of fossil fuels, reducing or eliminating the greenhouse gas emissions from these fuels. The use of HTGRs also provides a more secure energy source and insulates the end user from the economic problems associated with the volatility in the price of fossil fuels.

The project's scope includes design, construction, licensing, and operation of a full-scale prototype HTGR plant and associated technologies as applied to an initial industrial application. This scope will establish the technological and licensing basis for expanded commercial applications and develop the infrastructure necessary for the commercialization of this new generation of advanced nuclear plants. NGNP is scheduled to be operational by 2021 , as required by the EPAct. R\&D will also be completed in regard to other potential commercial industry applications.
This report provides a brief overview of the background of HTGR technology relative to NGNP and describes the progress and accomplishments to date, as well as the program execution plan for project completion.

\section{Background of HTGRs}

An HTGR is a graphite-moderated nuclear reactor cooled by helium that operates at high temperatures in the range of 700 to $950^{\circ} \mathrm{C}$, enabling process heat to be used for diverse chemical process applications and hydrogen production as well as electricity production. Key characteristics of the HTGR concept are the use of helium as a coolant, graphite as the moderator of neutrons, and ceramic-coated particles as fuel. Helium is chemically inert and will not react under any condition. The graphite core slows down (moderates) the neutrons and provides high temperature strength and structural stability. The ceramic-coated fuel particles are extremely robust and retain the radioactive byproducts of the fission reaction under any condition.

Two major design concepts - a prismatic block reactor and a pebble bed reactor-are currently under consideration for the HTGR. The prismatic block reactor core configuration consists of hexagonal graphite blocks stacked to fit in a circular pressure vessel. Cylindrical passages are located within each block for the helium coolant and for graphite cylinders that contain the coated particle fuel. Additional graphite blocks surround the core to shape and reflect the neutron flux. The reactor is refueled with blocks containing new fuel approximately every 18 months. The pebble bed design uses fuel particles that are formed into pebbles, approximately the size of a billiard ball, with graphite reflectors surrounding the pebbles to provide structural support of the core and reflect neutrons back into the core. The pebbles continuously circulate through the core and are re-circulated six to ten times over the course of three years before being permanently discharged from the reactor. Fresh fuel pebbles are added to replace those discharged.

Both HTGR concepts are based on tri-isotropic (TRISO) coated fuel particles. Such fuels, which have been extensively studied around the world over the past four decades, consist of uranium

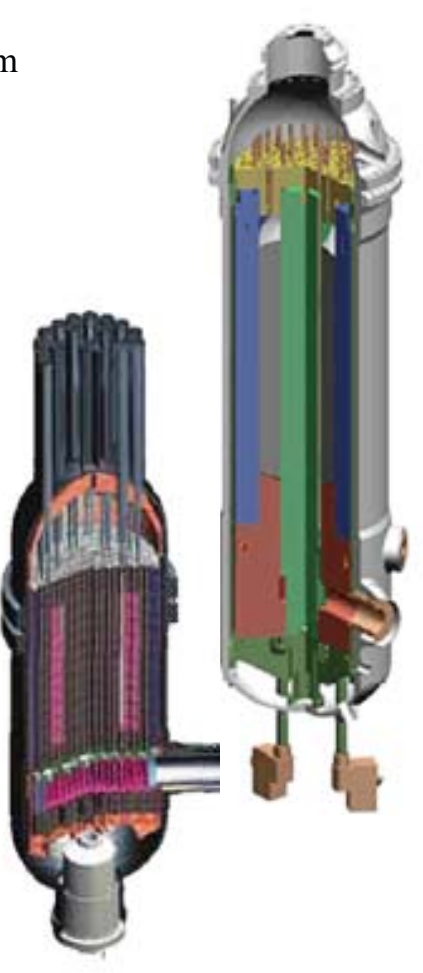

Figure 1. Artist rendering of two high temperature gas-cooled reactors (Pebble-bed and Prismatic). 
kernels (the active portion of the particle) surrounded by multiple layers of carbon and silicon carbide. HTGRs would contain billions of these particles, which are themselves encased within larger structures in the form of either small cylinders called compacts or billiard-ball-sized spheres called pebbles.

The TRISO layers provide robust protection for the nuclear material and outstanding retention of the radioactive byproducts produced during fission. Extensive testing in Germany in the 1970s and 1980s demonstrated that outstanding performance of high-quality, low-defect TRISO-coated particle fuels under both normal operation and potential, but highly improbable, accident conditions can be achieved. This outstanding performance, combined with large graphite reflectors that act as massive heat sinks, contribute to the passive safety of the concept. Such safety features allow HTGR reactors to be located close to industrial complexes where they can provide heat for high temperature chemical processes and hydrogen for chemical and petrochemical industries, which is the major objective of the NGNP Project.

The HTGR envisioned for NGNP is an extension of past applications of gas-cooled reactor technology. A number of prototype and demonstration HTGRs have been operated over the past 60 years that focused on the generation of electrical power. Two such reactors, one at Fort St. Vrain and one at Peach Bottom, have been licensed by the Nuclear Regulatory Commission (NRC) and operated commercially in the United States. Internationally, both pebble bed and prismatic block reactors have been

Figure 2. Previous
HTGR prototype
and demonstration
plants, showing that
this is not a new
technology.

licensed and operated in the United Kingdom, Germany, Japan, and China. Photos of some of these facilities are shown in the Figure 2. With the historical focus of these plants on producing electricity, modifications and adaptations will be needed to enable process heat produced by the NGNP to meet the project's mission.

\section{Project Accomplishments}

\section{R\&D Accomplishments since Project Inception}

From the inception of the NGNP Project, Idaho National Laboratory (INL) has led the collaboration of experts from DOE national laboratories, universities, and nuclear system suppliers to establish technology R\&D roadmaps. These roadmaps (1) outline the testing and computational development activities needed to qualify the materials and validate the modeling and simulation tools to be used in designing and safely operating the NGNP; (2) draw upon worldwide experience gained from the seven prototypical HTGRs built and operated over the past 60 years; (3) provide detailed descriptions of the required technical activities with associated schedules and budgets for project completion; and (4) form the baseline for executing R\&D needed for the NGNP Project. The R\&D activities are organized into four major technical programs: (a) Fuel Development and Qualification, (b) Graphite Qualification, (c) High Temperature Materials Qualification, and (d) Design and Safety Methods Validation. Each technical program researches concepts that will enable NGNP deployment through development of data for NRC licensing

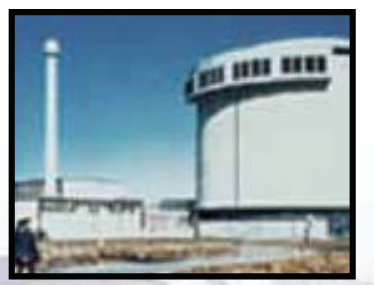

Dragon (England) 1963-1976

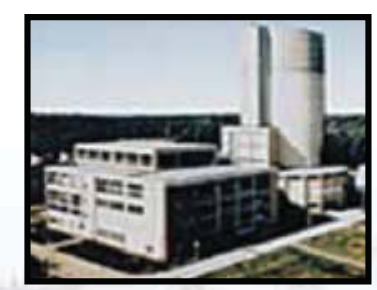

AVR (Germany) 1967-1988

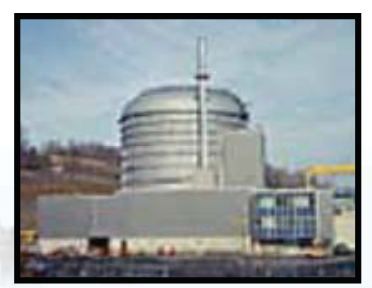

Peach Bottom

(U.S.) 1967-1974

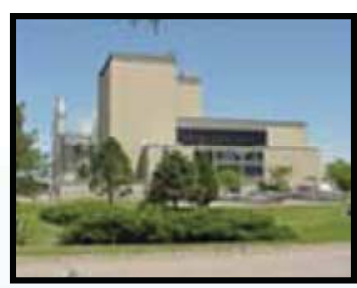

Fort St. Vrain (U.S.) 1976-1989

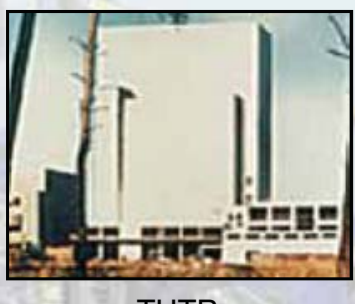

THTR

(Germany) 1986-1989

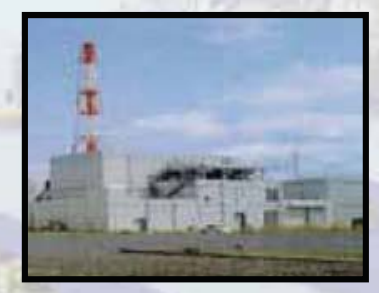

HTTR

(Japan) 1999-present

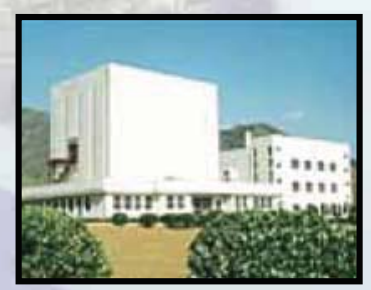

HTR-10

(China) 2000-present 
as well as through resolution of data needs identified by reactor suppliers who will design the plant systems. The objectives, current status, accomplishments to date, and future plans of each technical program area are discussed at a high level in this section. The details are presented in Appendix A (see CD provided with report). To accomplish project objectives, the R\&D program draws upon expertise at DOE national laboratories and a broad array of universities along with international facilities and expertise.

\section{Fuel Development and Qualification}

The HTGR concept is based on coated particle fuels such as shown in Figure 3. The fuel is made up of tiny uranium kernels coated with layers of carbon and silicon carbide, forming particles. Billions of these particles are distributed throughout a carbon matrix and shaped into either small cylinders (compacts) or billiard-ballsized spheres called pebbles (see Figure 3, for additional detail regarding fuel or any other R\&D topic, please see Appendix A). Rigorous control is applied at every step during the fabrication process to produce high-quality, very low-defect fuel. Defect levels are typically on the order of one defect per 100,000 particles.
The main objective of the Fuel Development and

Revision 0

Qualification program is to qualify the coated fuel particle in order to facilitate NGNP's obtaining an NRC license to co-locate, build, and operate the plant near end-user industrial applications. The commercial manufacture and operating use of very high quality fuel results in the retention of nearly all fission products within the fuel structure, which greatly reduces the potential for any offsite radiological release during an unlikely plant accident. Achieving the fuel qualification objective requires extensive understanding of the behavior of the fuel during both operating and off-normal or accident conditions to ensure effective and safe operations. Because of the safety function provided by the fuel, the fabrication approach must be well understood to achieve this qualification.

The Fuels program has defined and made progress in several goal areas:

- Develop a robust fabrication approach for coated particles and the macro fuel form (either compacts or pebbles). Before the fuel can be tested or used in the plant, it must first be manufactured on an industrial scale. The inherent safety features of the fuel are created during this process. Historically, the United

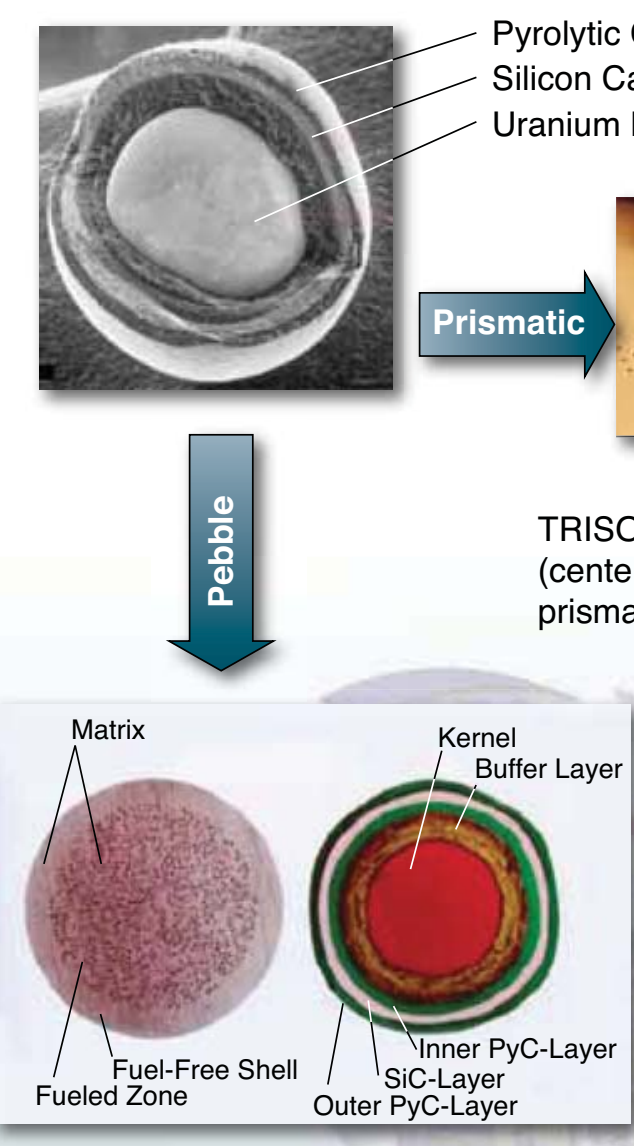

TRISO-coated fuel particles are formed into fuel spheres for pebble bed reactor
TRISO-coated fuel particles (left) are formed into fuel compacts (center) and inserted into graphite fuel elements (right) for the prismatic reactor

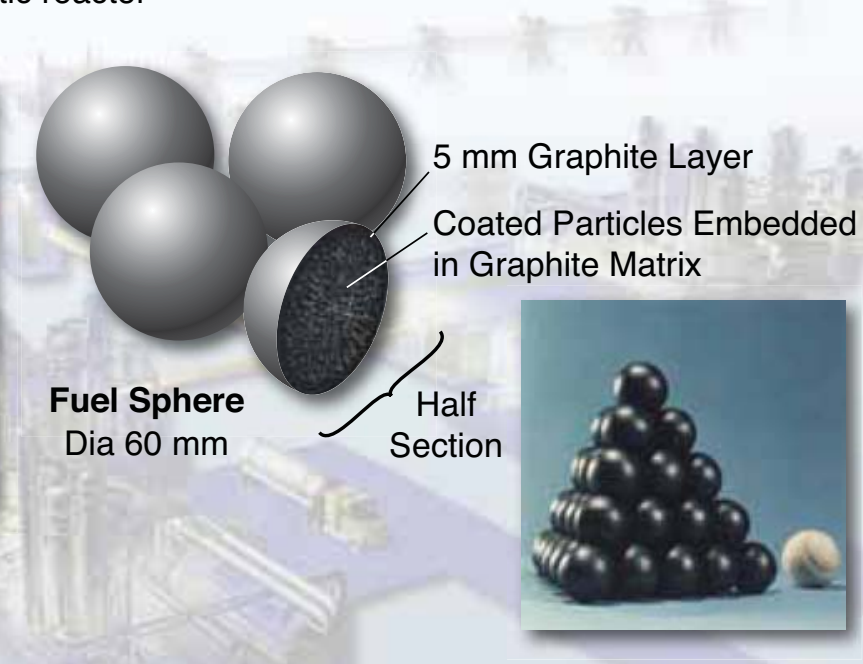




\section{Revision 0}

\section{Advanced Nuclear Fuel Program sets global performance record}

NGNP scientists set a world record with next-generation particle fuel (to be used in new high temperature gas reactors [HTGRs]) by using approximately $19 \%$ percent of its low-enriched uranium - more than double the previous record set by German scientists in the 1980 s and more than three times that achieved by current light water reactor (LWR) fuel. In addition, none of the fuel particles experienced failure after entering the neutron irradiation test environment of Idaho National Laboratory's (INL) Advanced Test Reactor (ATR) in December 2006.

The nearly 3-year experiment subjected more than 300,000 nuclear fuel particles to an intense neutron irradiation field and temperatures around $1,250^{\circ} \mathrm{C}$. The fuel is made up of many particles (This particle is $\sim 1 / 32$ inches in diameter. See picture) combined with more carbon and shaped into either billiard-ball sized pebbles or much larger honeycomb-like prisms.

Each fuel particle contains a kernel of enriched uranium surrounded by carbon and carbide layers that act as containment boundaries for containing and protecting the radioactive material. With this kind of self-protecting fuel, HTGRs can be located close to industrial complexes where the reactor heat can be used in place of fossil fuels to produce electricity, hydrogen, etc.
States and Germany developed expertise in manufacturing gas reactor fuel. U.S. expertise in fabricating coated particle fuel was lost in the 1990s. Beginning in the early 2000s, this expertise has been reestablished through the laboratory- and industrial-scale development efforts of DOE national laboratories and fuel vendors. This development has extended previous understanding of critical mechanisms causing fabrication parameters to drive fuel performance and converting what was an art into a well-grounded scientific understanding. This was done while keeping the high standards of fuel quality, meeting and exceeding the goal of only one defect per every 100,000 particles at an industrial scale.

- Understand behavior of the macro fuel form and particles under operating and potential but highly unlikely accident conditions. TRISO fuel must perform during reactor operation, where performance includes not only sustaining the energygenerating reactions but also retaining the fission products during irradiation at high temperatures. NGNP tested close to 300,000 particles in the first test of the fuel irradiated over the last three years in the Advanced Test Reactor (ATR) at Idaho National Laboratory (INL). No failures were detected, meaning the fuel performed exceptionally well and retained those fission products, thus fulfilling the intended function of the fuel to increase the safety of HTGRs. The fuel also achieved records for using as much as $19 \%$ of the energy contained in the material (previous records achieved less than 10\%). This irradiated fuel will be examined in great detail for both physical specifications and fission product retention after having been heated to temperatures well above the operating range to simulate postulated accident conditions. This examination will establish initial understanding of the fuel's operating and safety behavior in this wide range of conditions. The second fuel irradiation test, one with fuel manufactured using industrial-scale processes where the shakedown test included only laboratorymanufactured particles, is ready to begin.

These accomplishments, combined with state-ofthe-art fuel modeling and simulation capabilities developed to predict fuel performance, position the Fuel Development and Qualification program to achieve its objectives.

\section{Graphite Qualification}

Graphite has been effectively used in the past as structural material for high temperature reactor cores. Historical grades of graphite and the supply of raw feedstocks used in gas reactors no longer exist. The objective of the Graphite Qualification program is to demonstrate that modern grades of nuclear graphite made with current feedstock materials will perform as well as historical grades that are not currently available. The program also has a goal to understand the complex behavior of graphite in the nuclear environment at a deeper scientific level relative to its overall performance in HTGRs.

A testing program was designed to prove graphite performance and understand its behavioral characteristics. The elements of the program and its accomplishments are described as follows:

- Graphite characterization. To understand the behavior of graphite during irradiation, it needs to be extensively examined prior to being placed in a reactor. A significant effort was thus completed in developing graphite characterization capabilities at both INL and Oak Ridge National Laboratory (ORNL). This task consisted of procuring, setting-up, and calibrating state-of-the-art analytical test equipment and developing test protocols to 
accurately and repeatedly measure graphite characteristics. Large graphite billets were procured and are being examined in preparation for future experiments to be placed in the ATR.

- Irradiation. A test program was established to vary the important parameters that will have the greatest impact on graphite performance while in service, including temperature, weight loading, and level of neutron exposure to the graphite. The first experiment has been placed in the reactor and is being irradiated over the next two years. The experiment itself uses a worldclass design developed for this application to understand the behavior of graphite with weight loading and neutron exposure at high temperatures. The experiment is monitored by significant instrumentation needed for on-line management and experimental data collection. Extensive post-test examinations are planned to understand the key material property changes caused by irradiation exposure. These irradiation data and the as-fabricated material properties will be used to improve the detailed modeling and simulation tools currently being used to predict the structural response of graphite throughout the reactor core. The data from all characterization and modeling activities is needed by the American Society of Mechanical Engineers (ASME) to certify the structural adequacy of graphite during the HTGR licensing process.

\section{High Temperature Materials Qualification}

The high outlet temperatures of HTGRs necessitate the development of high performance metallic alloys to transfer heat from the reactor to the application process. Because these alloys will contain the high-pressure helium used to cool the reactor, stringent requirements are imposed to ensure that this piping and the equipment through which the helium flows, called the pressure boundary, will maintain its integrity. Thus, the goal of the High Temperature Materials Qualification program for NGNP is to obtain the performance data required to support the development of these high temperature components over the range of envisioned outlet temperatures that would apply to most industrial applications.

Similar to the Graphite program, a significant effort was expended to develop testing capabilities so the environmental conditions of the heat transport system, including temperature, pressure, and gas mixtures, could be replicated while simulating the long durations of heat transport system service life. Existing testing methods did not allow for repeatable and accurate measurement of the parameters of interest. To address this challenge, the program developed new protocols using approved ASME approaches that allowed for repeatable measurements (see Figure 4). Results have been gathered for some materials of interest and will continue beyond selection of the final materials of construction in order to either extend existing ASME code cases (the qualification approach for high temperature metals) or establish new cases for metal alloys in new service conditions. Future developments include enabling the inspection of metals in the heat transport system during reactor operations.

\section{Design and Safety Methods Validation}

The goal of the NGNP Design and Safety Methods Validation program is to develop the experiments and data needed to validate modeling and simulation tools used to establish the design and safety of the HTGRs being developed by the NGNP Project for industrial applications. The program has participated with the NRC by using a well-established expert input process to rank important events that might occur during an unlikely accident. Simulations were developed to model the behavior of the reactor core and other systems during these events, allowing many more situations to be examined than those that can be demonstrated during a physical test. By correlating simulation outputs to individual known reactor parameters or experiments, the simulations can be a powerful tool for examining the ranges of operating parameters critical to safety performance in a continuous way, rather than looking at discrete point results. The program has partnered with such international collaborators as the Japanese High Temperature Test Reactor and such universities as Oregon State University to share data and collaborate on experimental programs to maximize the progress that can be made within schedule and budget limitations. 


\section{Technology Readiness}

The NGNP Project established a technology risk management activity to assess the technical risk

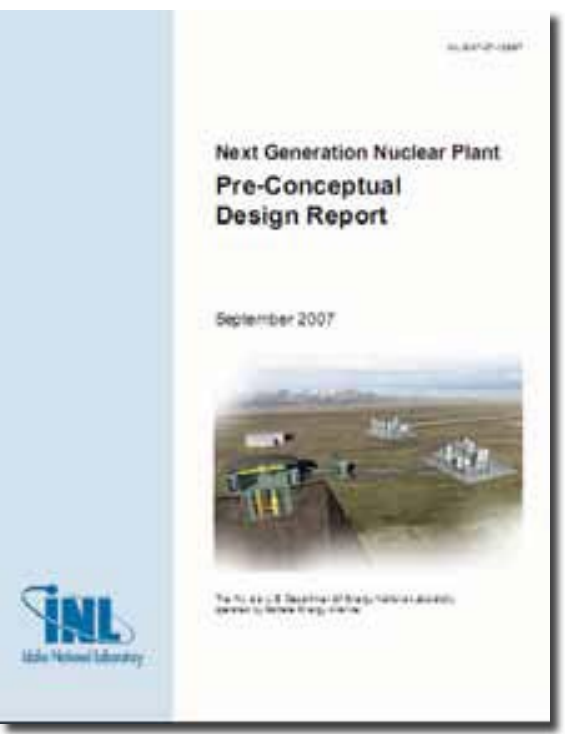
and integrate all $\mathrm{R} \& \mathrm{D}$ activities with the necessary design and licensing activities anticipated for the NGNP. The approach is based on National Aeronautics and Space Administration and Department of Defense technology risk efforts, which rely on Technology Readiness Levels for a consistent framework in determining the maturity of a technology with respect to a specific application. Testing programs are then established to increase the maturity by enhancing the correlation between the testing conditions and specific conditions in the nuclear plant, thus increasing the

Figure 5. The NGNP Pre-conceptual Design was issued in 2007.

\section{* The EPAct also} includes provisions that require the DOE to enter into a partnership with the private sector for completion of the Project on a cost-shared basis. In early 2006 a consortium of privatesector companies, which is called the Industry Alliance today, was initiated with the objective of forming a publicprivate partnership for execution of the project. The current Industry Alliance includes the three HTGR nuclear system suppliers, potential end users and a current nuclear power plant Owner/Operator (Entergy). physical scale of the test or integrating multiple systems to better model operating conditions. By establishing the extent that the technology can mature during a test or series of tests, the project can prioritize budget allocations based on which efforts provide the best increase in maturity. This philosophy guides overall project planning and integrates $R \& D$ activities with planning for design and licensing while reducing the overall project risk.

\section{Future Plans}

Given the need for specialized facilities such as nuclear test reactors, hot cells, and specialized high temperature/high pressure testing facilities, acquiring the R\&D data needed to qualify NGNP fuels, materials, modeling, and simulation tools for licensing will be accomplished over a multi-year schedule. Near term R\&D is therefore focused on continuing qualification activities in the areas of fuel development, graphite qualification, high temperature materials qualification, and design and safety methods validation to reduce risks and develop the data needed for plant design and licensing.

\section{NGNP Engineering Accomplishments since Project Inception}

Engineering efforts began in earnest in FY 2007 to (1) initiate the design, thereby advancing the project towards its overall goal of licensing and deploying the NGNP, and (2) identify open questions with respect to technological aspects of the NGNP that would need further resolution by R\&D. Beginning preconceptual design activities also allowed significant steps to be taken toward fulfilling an expectation of the authorizing legislation, thereby having significant industrial involvement, both from a nuclear-system-supplier and end-user perspective.

\section{NGNP Project Pre-conceptual Design}

In late FY 2006, the NGNP Project issued a request for proposals to perform preconceptual engineering for an HTGR plant that produces both electricity and hydrogen. Technically acceptable proposals were received from three teams headed by HTGR system suppliers: Westinghouse / Shaw / PBMR (Pty) Ltd, AREVA, and General Atomics. This preconceptual work was completed in FY 2007, culminating in the submittal of individual preconceptual design reports from each team and a consolidated report issued by the Project.

These plants include both pebble-bed reactor and prismatic block gas reactor designs with rated power levels from 500 to $600 \mathrm{MWth}$ and reactor outlet temperatures from 900 to $950^{\circ} \mathrm{C}$. The plants produced both electricity and hydrogen, employing high temperature electrolysis, sulfur iodine, and, for the latter, hybrid sulfur processes. The schedules were developed with the objective of beginning initial operation of the NGNP at the end of 2018, three years before the EPAct objective of 2021.The NGNP Project's reconciliation of cost estimates provided by the teams estimated the total project cost to be $\$ 3.8$ to $\$ 4.2$ billion in 2007 dollars.

\section{Nuclear System Supplier and Potential-End-User Input Defines the Scope of the Project}

NGNP's authorization language requires the project to "maximize the technical interchange and transfer of technologies and ideas into the Project from other sources of relevant expertise, including... the chemical processing industry, particularly with respect to issues relating to(a) the use of process energy for production of hydrogen; and (b) the integration of technologies developed by the Project into chemical processing environments..." The NGNP Project pursued a strategy in FY 2008 of integrating the industry needs into the project requirements to both enhance industry interest in commercial deployment and reduce technical risk. 


\section{Initial Understanding of Industry Needs}

In FY 2008, the NGNP

Project worked with

contractor teams and

a partnership called

the NGNP Industry

Alliance* to complete a

comprehensive review of

project objectives with

potential end users of

the HTGR technology.

This effort included

a literature review of

industry uses of energy to

characterize the quantities

of energy used in candidate processes and

the characteristics of the energy such as type,

temperature, and pressure. Much of this work

was coordinated with a Senior Advisory Group

made up of representatives from nuclear system

suppliers and the Industry Alliance. This Senior

Advisory Group has met regularly over the

course of the project, providing recommendations

on configurations and operating conditions for the

NGNP.

The potential end users include major companies involved in petrochemical, refining, fertilizer manufacturing, oil sands and oil shale recovery and refining, coal mining, and other industrial processes. In general, the characteristics of the energy used in these processes, such as temperature and the form of the energy supply, fall within the capabilities of the HTGR technology as shown in Figures 6 and 7.
Revision 0

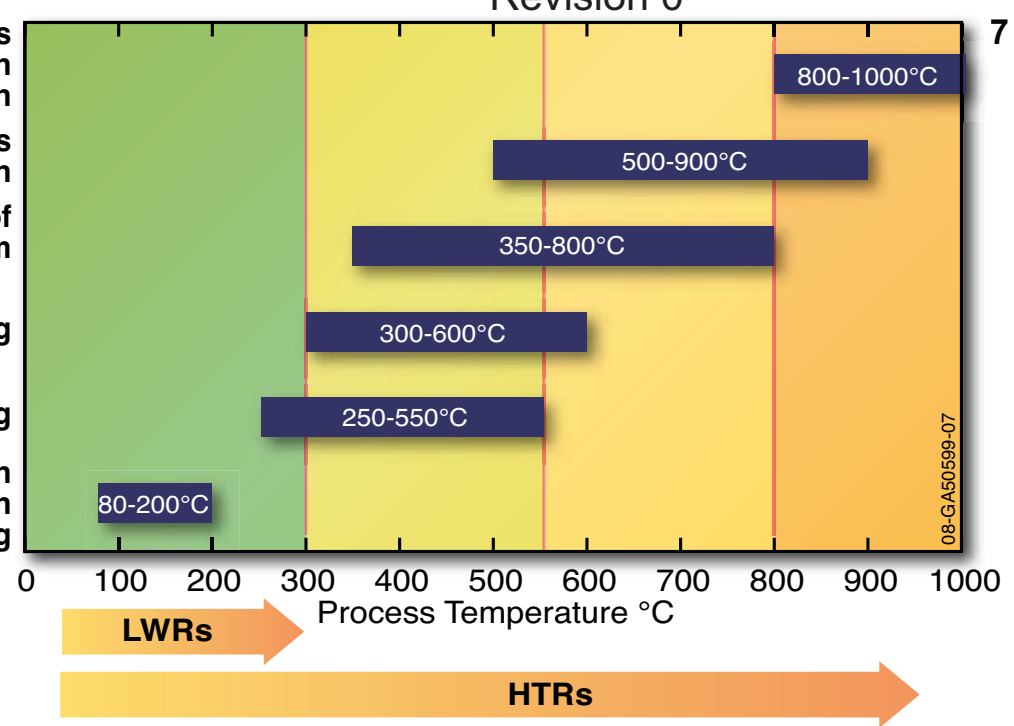

Figure 6. Summary of temperature requirements for potential end users of HTGR technology.
- Reactor outlet temperatures in the 700 to $800^{\circ} \mathrm{C}$ range would be sufficient to satisfy the initial temperature needs of industry; pursuit of higher reactor outlet temperatures should be continued for future higher temperature applications.

- Multiple modules of nuclear heat supply systems will be required to satisfy the total energy needs and availability requirements of the processes.

- Steam, electricity, and hot gas are the principal forms of energy required to satisfy the current needs.
Figure 7. Near term HTGR application annual energy demand vs. temperature.

These evaluations reached the following conclusions:

- The industry would be interested in applying the HTGR technology if it can be supplied no later than early in the 2020s.

- The initial application of the technology should be in a commercial application rather than as a demonstration

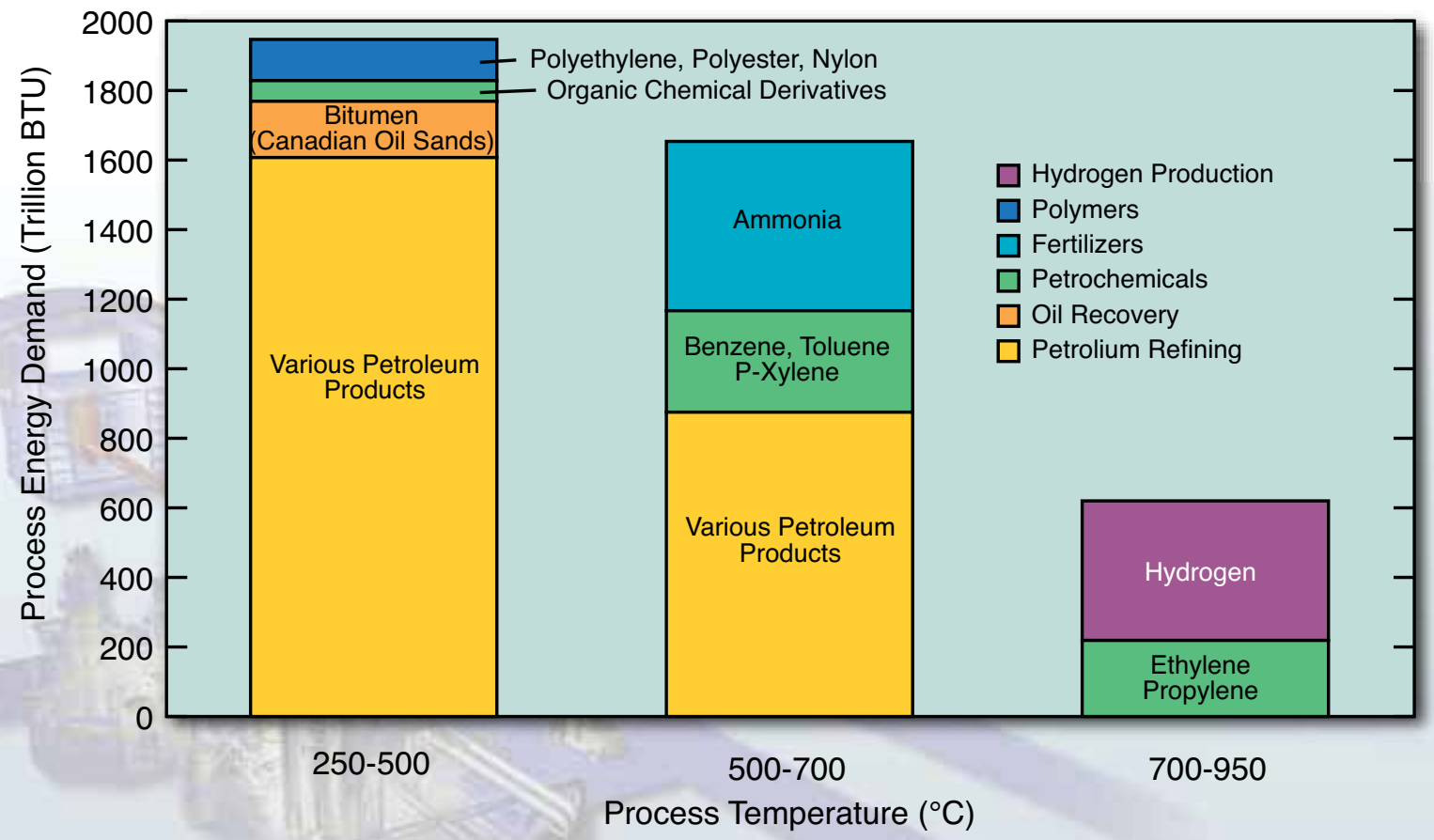




\section{Revision 0}

- Along with supplying steam, electricity, and hot gas, an economic supply of hydrogen from the HTGR would permit the upgrade of current industrial processes to increase efficiency and reduce greenhouse gas emissions (e.g., petrochemical processes, conversion of coal to synthetic fuels, fertilizer manufacturing).

\section{Revisions to Risk Management Plan and Nuclear System Supplier Plant Design Approaches}

Throughout FY 2008, reductions in temperature for the first-of-a-kind plant were factored into the (a) NGNP Risk Management Plan, (b) ongoing technology readiness assessment of critical components, (c) definition of design data needs, and (d) costs to complete the project. The NGNP R\&D and licensing plans for engagement with the NRC were established. Costs for these programs, including engineering support, were also developed. At the end of FY 2008, the total project cost (sunk and to-complete) was estimated at $\$ 4.8$ billion in 2007 dollars and the date for initial plant startup was the end of 2021, consistent with the EPAct provisions.

The nuclear system suppliers also revised the recommended configurations and operating conditions for the NGNP to be consistent with recommendations they made previously. These configurations and operating conditions are discussed in detail in Appendix B.

\section{FY 2009 Revisions to NGNP Project Planning}

FY 2009 plans to complete project engineering and the designs proposed by nuclear system suppliers for the first-of-a-kind plant were hindered by several factors. The intention was to begin conceptual design activities in FY 2009 with the nuclear system suppliers already under contract. However, DOE determined to apply the cost sharing from the EPAct to conceptual design activities. To that end, DOE developed a Funding Opportunity Announcement (FOA) for sharing cost in the development of as many as two conceptual designs for the NGNP.

As the FOA was being developed, the project and DOE identified generic engineering scope and trade studies that could be executed without supporting a specific design, and would inform ongoing R\&D or licensing activities. This scope was then successfully executed in FY 2009, which included (a) updating technology roadmaps that lay out $R \& D$ activities needed to mature technologies sufficiently to be ready for their deployment in NGNP (as described at the end of the R\&D section above), (b) identifying differentiating parameters in selecting a power conversion system (electricity-generating part of the plant), (c) developing fission product transport analyses, (d) updating costs from the pre-conceptual designs, and (e) evaluating how NGNP could be coupled with industrial applications and the economic and environmental (reduced carbon emissions) impact of such coupling.

The technology roadmapping process also identified a significant number of tests that are needed to mature HTGR technologies but have not been associated with an existing facility or capability because they need to be performed at larger scales and in an integrated fashion. A separate project was therefore identified to either locate existing capabilities to conduct these tests or develop a set of capabilities as associated infrastructure. This is called the Component Test Capability (CTC) project.

Conceptual design of the NGNP will not begin until the FOA process has concluded with one or more design teams selected and terms and conditions negotiated. The start of the design may not occur until the third quarter of FY 2010 or later. The impact of these delays associated with commencing conceptual design will have to be evaluated at the conclusion of the conceptual design period.

\section{Technical and Commercial Challenges Affecting Plant Deployment}

Throughout preconceptual design and industry end-user interactions, a number of issues affecting the NGNP design were identified that need to be addressed and resolved during the initial phases of conceptual design. How these issues are resolved will affect the cost of the plant, the schedule for completion, the range of commercial applications to which the plant can be applied, the approach and scope of licensing by the NRC, and the economics of the HTGR application. Completion of this project in a time frame that is of interest and use to industry (initial plant operation in 2021) requires that the reference configurations and operating conditions be established and the issues listed herein begin to be addressed and resolved in FY 2010 or FY 2011 so that design, licensing, cost, schedule, 
and economic factors can be established with sufficient confidence to confirm HTGR technical, licensing, and economic viability.

The issues affecting the NGNP design and deployment are briefly described in the following list (see Appendix B for more details):

- System Technology Readiness Levels. Critical systems, subsystems, and components must be sufficiently matured according to a schedule to support timely NGNP deployment. Many needs have been identified and some refer to specific development by reactor type, but most are generic and do not differentiate between reactor types, supporting the continued investigation of the two main HTGR reactor types.

- Completion of $R \& D$ and associated qualification programs. There are four significant R\&D areas moving forward (Fuels, Graphite, High Temperature Materials, Design and Safety Methods). Each will develop data critical to design and licensing of the plant. In particular, both the level of protection against fission product transport that is provided by each barrier to release and the mechanisms/effects associated with air and water ingress into the core under accident conditions must be better understood.

- Development of Analysis Codes. Many of the computer codes used by nuclear system suppliers were developed several years ago. These codes therefore need to be updated to reflect current experimental and development work and modernized to run on today's computer platforms.

- Supply of fuel and graphite. Little work has been done to date to ensure the overall infrastructure is in place to produce and supply the amounts of material with the stringent quality requirements needed for both the first-of-a-kind NGNP and followon reactors that will leverage the design and licensing work of the NGNP.

- $\quad$ ASME/ASTM Code Case Development. Licensing activities and material supply rely on code cases being in place for materials of construction. While the recent reduction in reactor outlet temperature should reduce this effort, existing code cases will, at a minimum, need to be updated or extended. However, qualification of materials at higher temperatures provides for greater safety margins and broader applications.

- Infrastructure for supplying other key materials and services. Large vessel components, helium circulators, ceramics, and controls, high-temperature valves,

and hydrogen processes are some of the components and capabilities needed to make NGNP successful. The infrastructure to competitively provide all of the above requires development, since it is either immature or not yet in place.

- Component Test Capability. As previously stated, a significant number of tests have been identified to reduce technical risk to the project, but the capability to perform these tests does not currently exist. Studies have been performed to identify the requirements for providing such capability, and the effort to identify or produce such capability is contained in the CTC. A mission need statement is currently under consideration for a project to develop such a capability, but in its absence, risk mitigation or acceptance methods will have to be reconsidered.

- Hydrogen Processes. Though there are promising approaches for using HTGR process heat to produce hydrogen, developmental opportunities still need to be explored in this area. The scope for this development effort has been transferred from the now concluded Nuclear Hydrogen Initiative to the NGNP Project.

- Cost and schedule estimate confidence level. Existing cost and schedule estimates for the NGNP are based on data from the FY 2007 preconceptual design, which has higher outlet temperatures and different plant configurations than those likely to result from conceptual design. Some adjustments have therefore been made based on trade studies in the interim period, but without additional design efforts, current estimates may lack both precision and accuracy with respect to the final results.

- $\quad$ Product contamination. As the NGNP is intended to provide process heat to industrial applications, it is critical that the fluid (helium or steam) carrying the heat be sufficiently pure to not contaminate downstream products. Existing specifications for those end-user products do not cover
Figure 8. Research and Engineering are addressing several technical and commercial challenges to ensure successful NGNP deployment. 
nuclear-type contaminants, which must be considered for the anticipated specification needs.

- Co-location and/or integration with industrial processes. HTGRs providing heat for industrial applications will need to be located close to the given industrial facility to reduce heat loss in transport. This will require an understanding of enhanced safety features offered by the HTGR such that typical distance buffers expected between LWRs and other facilities can be reduced. Additional considerations may arise from integration with petrochemical refining or exploration activities.

- $\quad$ Multiple modules. Providing adequate process heat to meet the capacity and availability needs of industry may require that multiple reactor modules be located at a given facility. It may also be advantageous to operate these plants from a single control room. These configurations are outside of the normal paradigm associated with LWRs, and issues arising from this new approach need to be explored.

\section{Licensing Accomplishments since Project Inception}

The NGNP will be licensed by the NRC.

The NGNP Project has therefore adopted the

Combined License (COL) application process in 10 CFR 52, as recommended in the Report to Congress, ${ }^{*}$ as the foundation for its licensing strategy. Licensing of the NGNP via this process will demonstrate the efficacy of licensing future gas-cooled reactors for commercial industrial applications. DOE and the NRC are now executing this licensing strategy, which involves DOE in identifying a specific reactor technology for the NGNP, and NRC in conducting the review.

The following sections describe recent NGNP Project accomplishments in the licensing area.

\section{Identified Highest Priority Licensing Issues for Focused Interaction with NRC}

\footnotetext{
* United States Department of Energy, "Next Generation Nuclear Plant Licensing Strategy, A Report to Congress," August 2008
}

In executing the licensing strategy, NGNP Project team members first conducted a review of gas reactor licensing history and precedents by performing an initial screening review of the applicable regulations and associated regulatory guidance the project would need to address. The

\section{Revision 0}

the NGNP Licensing Plan issued in June 2009.

The Licensing Plan establishes a regulatory framework and project licensing structure that will result in the successful licensing, construction, and operation of the NGNP. This plan focuses on resolving the most significant policy issues during interactions with the NRC, and outlines a licensing path for the NGNP that will lead to the approval and issuance of a COL by the NRC.

The highest priority issues generally fall into one of two categories:

- Have the potential for significant impact on the plant design and/or planned $R \& D$ activities

- Will likely require Commission action to resolve.

\section{Established Regular NGNP Project Interactions with NRC to Begin Issues Resolution}

As described in the Report to Congress, the NRC is expected to participate in the early NGNP Project licensing process. That early process includes the NGNP Project gathering information; identifying and developing proposals for resolution of key design, safety, and licensing issues; and preparing white papers identifying programmatic, regulatory, and key technical issues with recommendations for consideration and approval by the Commission. Frequent, focused, and coordinated interactions between NRC and NGNP Project staff will be critical to the success of the project. The following steps were taken to support these interactions:

1. The NRC established and staffed an Advanced Reactor Programs Branch, with a project team assigned to review the HTGR licensing issues associated with the NGNP Project.

2. The NGNP Project team engaged NRC staff in initial public meetings regarding the resolution of priority licensing issues.

Commenced the Development and Submittal of NGNP White Papers Addressing Priority Licensing Topics screening results were then incorporated into
The NGNP Project team is analyzing a number of the highest priority licensing topics and compiling their findings into a series of licensing white papers that will form the basis for adapting existing regulatory requirements to the licensing 
of HTGRs. These papers will be submitted to the NRC for their review. Resolution of the topics described in these papers will then be achieved through a series of NRC public meetings and responses to $\mathrm{NRC}$ requests for additional information. The objective of this effort is to document these resolutions in NRC guidance (Interim Staff Guidance, Commission Policy Statement, etc.), thus providing a firm basis for the NGNP license application.

The first white paper was submitted to the NRC for review on December 9, 2009. This paper covered the topic of defense-in-depth, which forms a key part of the risk-informed performance-based licensing approach described in the Report to Congress. Other papers nearing completion are expected to be submitted to the NRC during the third quarter of FY 2010. These papers will cover topics associated with qualifying fuel, qualifying high temperature materials, and defining mechanistic source terms.

\section{Obtained Agreement on the Development of a COL Content Guide}

The project team obtained an initial agreement with NRC staff regarding the development of a COL application content guide. This jointly developed guide will contain a detailed description of the required technical and licensing material that must be included in the NGNP COL application when it is submitted to the NRC for review and approval. The content will be based on the resolution of issues presented in the licensing white papers described above, and the resolution of other lower priority issues associated with the adaptation of LWR requirements to the licensing of HTGRs. This guide is expected to be similar in format and content to NRC Regulatory Guide 1.206, which includes detailed guidance for LWR application development and has been successfully implemented by the LWR community in conjunction with the one step, Part $52 \mathrm{COL}$ licensing process.

\section{Updates to NGNP Licensing Strategy (August 2008 Report to Congress)}

Based on current experience from early design activities and interactions with the NRC concerning additional development of the licensing strategy and approach, minor changes to elements of the August 2008 Report to Congress are necessary to ensure that the report effectively documents the current and future execution of the

licensing process. It is important to emphasize

that the overall strategy and approach, as

summarized in the subsections that follow, have

not changed. The subsection on page 12 describes

the need and details of the minor changes to the

licensing strategy.

\section{Report to Congress-Summary of Recommended Licensing Approach}

The Report to Congress concludes that the best alternative for licensing the NGNP prototype will be for the applicant to submit a COL application under Subpart C, "Combined Licenses," of 10 CFR 52 "Licenses, Certifications, and Approvals for Nuclear Power Plants." This recommended licensing approach is expected to take advantage of the new one step plant licensing process, which is expected to reduce both licensing risk and attendant financial risk compared to other available licensing options. Risk is reduced because the NRC has to approve the final design, site, verification criteria, and operational and procedural aspects of the application before any significant construction begins. This licensing approach is expected to ensure the most effective and efficient use of NRC and applicant resources while minimizing licensing risk and taking no longer than other alternatives to complete. This licensing approach should also reduce financial risk to the industry stakeholders funding the project.
Licensing Approach Focuses on Co-locating Reactors with Industrial Plants

In finding ways to decrease U.S. dependence on foreign oil and lessen greenhouse gas emissions (reduce our carbon footprint), scientists are looking to use heat from new high temperature gas reactors (HTGRs) in producing electricity, hydrogen, transportation fuels, plastics, and other chemical products. This will require these HTGRs to be located close to pertinent industrial complexes.

This scenario is facilitated by HTGRs' multiple safety barriers, starting with the fuel itself. HTGR fuel is made up of tiny uranium pellets wrapped in layers of carbon and graphite. These small particles are then encased in more carbon. Each layer and the overall carbon matrix provide a robust barrier that keeps the products that come from used nuclear fuel inside the fuel itself, even in unlikely but possible accident scenarios, thus preventing their escape to the atmosphere.

The Next Generation Nuclear Plant (NGNP) Project is working with the Nuclear Regulatory Commission (NRC) to reach a thorough and common understanding of the HTGR's multiple nuclear reactor safety barriers so that these barriers can be properly credited with protecting public health and safety, through the NRC's licensing process.

In partnership with private industry, the NGNP Project will test the HTGR process heat concept by designing, licensing, and operating an NGNP with actual industrial applications. The NGNP is projected to be operating in 2021. 


\section{Discussion of NGNP Project Implementation Consistent with the Recommended Approach}

The Report to Congress concluded that the licensing strategy should include the implementation of a risk-informed, performancebased approach as the most efficient means of adapting existing LWR requirements to the HTGR. It also recommended that the COL application be developed in accordance with the 10 CFR 52 one step licensing process. Actions associated with implementing this approach form the bases for the NGNP licensing plan described previously.

In implementing the planned licensing strategy, the NGNP Project team is focused on identifying and resolving programmatic, regulatory, and key technical issues early in the licensing process, since doing so could significantly impact the HTGR design and associated NRC license application. Any such impacts would then need to be adequately addressed through R\&D, design, and licensing activities, some of which could require long-lead efforts.

Near term NGNP licensing activities are focused on the following NRC licensing technical policy/ programmatic issues described in the Report to Congress, which are expected to require Commission involvement to address and resolve:

- Reconciliation of current NRC regulatory requirements that are focused on LWR technology with the safety basis of the HTGR technology

- Approach for using the probabilistic risk assessment to select licensing-basis events and establish defense-in-depth and special treatment requirements

- Establishment of allowable dose consequences for the licensing-basis event categories

- Establishment of an acceptable approach and basis for event-specific mechanistic source term calculations

As described by EPAct, Phase 2 includes continuation of research activities, development of a final design, application for NRC licenses to construct and operate NGNP, and construction and startup operations of the NGNP. licensing strategy, so the project is proceeding on the path identified through the implementation of the NGNP Licensing Plan, as described earlier. NGNP project activities continue to align with the proposed licensing strategy summarized in the 2008 Report to Congress. However, some of the key activities and associated milestones described in the strategy that directly support plant licensing and deployment are proceeding on a different timeline as summarized below (Report to Congress text in quotes):

1.1 “...DOE has not made a final determination on whether the license applicant will be DOE or one or more entities that reflect a partnership between DOE and private sector firms."

Update-DOE has determined that it will not be the sole applicant. The applicant will likely reflect a DOE and private sector partnership, as reflected in the recent $D O E$ Funding Opportunity Announcement (FOA). Per the FOA language: "If the project proceeds through Phase $2 *$, the applicant will be a public-private partnership. DOE will not be the sole applicant."

Section 2.1.3 of the Report to Congress includes a number of actions that were assumed would occur, in order to support EPAct target dates associated with the completion of construction and start of operation for the first plant. In general, the project is proceeding through those items, with the following exceptions noted:

2.1.3 "DOE chooses a single design no later than March 2009 to support the pre-application review."

Update-DOE is preparing to proceed with conceptual design activities through the contract award process associated with its FOA. Those activities may include the pursuit of more than one design. DOE plans that a single design be selected at the beginning of Phase 2 of the project. The conceptual design(s) completed in Phase 1 will inform the competitive selection of a single design. Since the selection will be beyond the March 2009 date assumed in the Report to Congress, the NGNP team has focused its efforts on high priority licensing topics that do not immediately require the information that would be available from a selected design. This approach is being implemented by the NGNP Project team in order to minimize any overall impacts on the resolution of key policy and technical 
issues with the NRC and the NGNP plant deployment schedule.

2.1.3 "The applicant submits a regulatory gap analysis in FY 2010..."

Update-Based on the current DOE approach, the license applicant will be selected as a part of the management team for Phase 2. This selection will follow a competitive solicitation, which will begin after a Secretarial decision whether to proceed with Phase 2, which is expected in January 2011. Therefore, the NGNP Project team will fill in for the applicant in developing a regulatory gap analysis, since the applicant will not be known in FY 2010. This is acceptable because the original assumption included in the Report to Congress was based on the gap analysis being performed by the applicant or DOE and its contractors.

2.1.3 "Programmatic, regulatory, and key technical issues identified during the preapplication review are resolved at least 1 year before the licensing application is submitted to ensure the incorporation of any design modifications. To achieve this, preliminary design descriptions of all safety-significant systems must be available at the beginning of the pre-application review (FY 2010), and the applicant must propose reasonable solutions to potential programmatic, regulatory, and key technical issues at that time."

Update-Because there is not an applicant prior to the beginning of Phase 2 execution, preapplication will not formally begin

until that time. Conceptual design reports completed by FOA awardees will include preliminary descriptions of all safetysignificant systems and anticipated solutions to selected programmatic, regulatory, and key technical issues. Conceptual design reports are scheduled to be completed by the end of 2010.

NGNP Project efforts to address and resolve priority licensing issues will proceed in parallel with the completion of safetysignificant design descriptions. Those descriptions will be available and integrated into a preapplication program, on or after the completion of Phase 1 (January 2011).

\section{Allocations of Funds Appropriated}

From FY 2006 through FY 2010, the NGNP Program was allocated \$528 million of the \$607 million allotted to the Generation IV Reactors Program. The NGNP Project, managed out of INL, has direct management responsibility for a majority of those funds after deductions for other very high temperature reactor-related R\&D and other DOE Office of Nuclear Energy priorities. The available remaining NGNP funds totaled $\$ 399$ million. In preparation for the FOA, DOE then allocated \$38 million of the FY 2009 appropriation and \$2 million of the FY 2010 appropriation, such that $\$ 359$ million will have been applied directly for HTGR technology development under the NGNP Project from FY

NGNP Cumulative Funding Profile 2006-2010

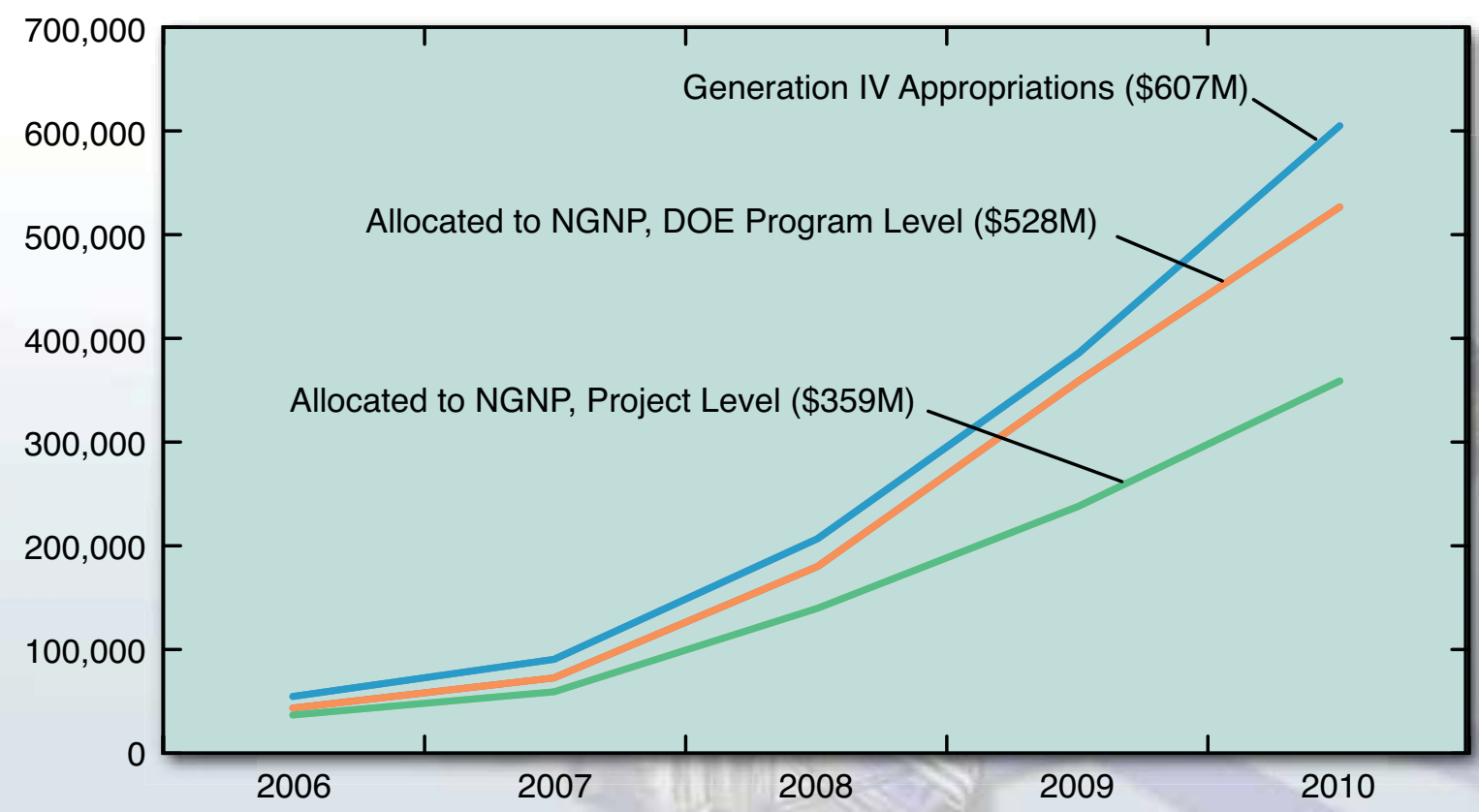

Figure 9. Cumulative Generation IV and NGNP funding since FY 2006. 
Revision 0

Table 1. NGNP Project funding allocation breakdown, in thousands.

\section{* Includes \$40,000k for FOA award and $\$ 175 \mathrm{k}$ for administration of the award process}

\begin{tabular}{|c|c|c|c|c|c|c|}
\hline Annual NGNP and Gen IV Funding & 2006 & 2007 & 2008 & 2009 & 2010 & Total \\
\hline NGNP Project Management & & 3,371 & 10,191 & 10,600 & 11,411 & 35,573 \\
\hline NGNP Fuel Develop & 15,800 & 4,513 & 23,665 & 32,011 & 32,192 & 108,181 \\
\hline NGNP Materials Development & 12,767 & 3,655 & 12,610 & 13,067 & 14,977 & 57,07 \\
\hline NGNP Design Method Development & 7,115 & 776 & 5,050 & 7,222 & 7,385 & 27,54 \\
\hline NRC Support for NGNP & & 1,750 & 3,250 & 2,505 & 3,000 & 10,505 \\
\hline NGNP Preconceptual Design (FY'07 \& & & 6,615 & 25,180 & & & 31,795 \\
\hline NGNP Special Design Studies & & & & 18,446 & 21,015 & 39,461 \\
\hline Holdback for Funding Opportunities Ann & & & & 37,813 & 2,362 & $40,175^{\star}$ \\
\hline NGNP Regulatory Affairs, Licensing & & 820 & 1,700 & 4,375 & 11,267 & 18,162 \\
\hline Component Test Capability & & & & & 1,900 & 1,900 \\
\hline Other NGNP Activities & 1,439 & & & & 4,646 & 6,085 \\
\hline $\begin{array}{l}\text { University Research Judged Applicable } \\
\text { to NGNP (NEUP) }\end{array}$ & & & & 10,337 & 12,668 & 23,00 \\
\hline Other University Research (NEUP) & & & & 20,674 & 25,336 & 46,010 \\
\hline Very High Temperature Reactor Deep Burn & & & 6,688 & 7,000 & 6,858 & 20,546 \\
\hline Russian Gas Turbine - Modular Helium & & & 8,396 & 1,944 & & 10,340 \\
\hline All Other VHTR Activities & & & 2,167 & 5,000 & 6,000 & 13,16 \\
\hline $\begin{array}{l}\text { Generation IV (Gen IV) International Forum } \\
\text { Support / International Collaboration }\end{array}$ & 1,008 & 1,349 & 1,424 & 953 & 1,900 & 6,63 \\
\hline $\begin{array}{l}\text { Nuclear Energy Research Initiative Awards } \\
\text { (Grants/Mortgages) }\end{array}$ & 1,615 & 5,427 & 5,078 & 3,905 & & 16,02 \\
\hline $\begin{array}{l}\text { Small Business Innovative Research (SBIR)/ } \\
\text { Small Business Technology Transfer (STTR) }\end{array}$ & 1,048 & 362 & 1,185 & 1,307 & 4,628 & 8,53 \\
\hline Rescission / Reductions & 550 & & 1,019 & & & 1,569 \\
\hline Technical Integration & 1,915 & 794 & 1,155 & 841 & 1,455 & 6,160 \\
\hline Other Gen IV R\&D & 11,743 & 6,154 & 7,242 & 2,000 & 51,137 & 78,276 \\
\hline Sum of Green (NGNP, Project Level) & 37,121 & 21,500 & 81,646 & 98,563 & 120,461 & 359,291 \\
\hline Sum of Green and Orange (NGNP, DOE Level) & 43,257 & 29,432 & \begin{tabular}{|l|}
108,758 \\
\end{tabular} & 178,000 & 169,000 & 528,447 \\
\hline Sum of Orange and Blue (Gen IV Level) & 55,000 & 35,586 & 116,000 & 180,000 & 220,137 & 606,723 \\
\hline
\end{tabular}

2006 through FY 2010. Figure 9 depicts the cumulative funding profile over time with these breakdowns. Table 1 itemizes these funds and categorizes them by Generation IV (blue), NGNP at the program level (orange), and NGNP Project (green).

Prior to FY 2006, a total of \$42 million was allocated to NGNP for R\&D (fuels, materials, design methods, and other reactor concept development) from FY 2001 through FY 2005.

Earlier sections describing R\&D activities and accomplishments (comprising Fuels, Materials, and Design Methods Development; Engineering Design; and Licensing) document the outcomes realized thus far and ongoing for these funding levels. The Project Execution section describes the rough-order-of-magnitude estimates for to-complete funding and potential cost share breakdowns.

\section{Project Execution}

While the scope of the NGNP project has been defined in the required authorization language, the plans for deployment of NGNP will be determined by (a) refinements based on industry input, (b) the scope of design work awarded through the Funding Opportunity Announcement (FOA) of September 2009, (c) recommendations as a result of the Nuclear Energy Advisory Committee's (NEAC) review for going forward with Phase 2, and (d) subsequent contractual scopes established in the Phase 2 public-private partnership. The NGNP Industry Alliance has also been active in developing their vision for NGNP project execution. The DOE's and Industry Alliance's approaches are described below as alternative strategies to achieve both the NGNP objectives and the larger strategic role the NGNP plays relative to greenhouse gas emissions reduction, dramatically improved energy security 
using indigenous resources and reduced energyand feedstock-price volatility.

\section{DOE Approach}

Based on interactions with DOE personnel, it is understood that DOE's approach for developing the NGNP currently consists of the following major elements:

- Complete the scope of design work awarded under the FOA by the end of 2010

- NEAC would review the NGNP conceptual design, provide recommendations for proceeding with Phase 2, and submit a report to Congress by end of December 2010. In January 2011, the Secretary would announce the path forward for Phase 2. The current strategy calls for a technology selection subsequent to the conceptual design review. It is therefore assumed that only one design would proceed into preliminary design

- The procurement process for Phase 2 would be completed by September 2011, with commencement of Phase 2 activities (preliminary design, beginning of PreApplication phase with NRC) by October 1, 2011

- The Combined License Application (COLA) would be submitted by September 2013, it would take NRC up to four years to review the COLA, and the license would be issued by October 2017

- Construction would commence in 2017, with the plant commencing operations in 2021.

\section{Cost Sharing (DOE Approach)}

The FOA describes the initiation of the demonstration component of the NGNP project and defines the beginning of the 50-50 cost share described in the EPAct. The best current cost estimate for the project to deploy a single plant is approximately $\$ 4$ billion through 2021 ; this estimate is based on preconceptual design level detail and is unescalated. DOE will receive new estimates as part of the conceptual design reports in 2010 .

\section{NGNP Industry Alliance Alternative Approach}

In November 2009, the NGNP Industry Alliance sent Secretary of Energy Steven Chu an implementation strategy for the NGNP. Their approach mainly differs from the DOE approach in terms of the private sector's perspectives on technical and business risk. This perspective

requires that there be a pre-agreed-to execution and decision framework for the entire project that is built around the following principles:

- First-of-a-kind HTGR functional and performance requirements are based on the energy needs of the customers (the end users) and determined jointly by DOE and the Alliance

- Plant designs to fulfill the functional and performance requirements are determined by the nuclear system suppliers

- Proceeding with various stages of Phases 1 and 2 of the Project are jointly decided by the $D O E$ and the Alliance

- The design(s) to be licensed and constructed are determined by the owner(s) of the plant

- Whether and where to construct a plant are jointly decided by the owner(s) and the end user(s)

- Whether to and what configuration(s) are to be design-certified are determined by the owner $(s)$.

This framework, codified in a public-private partnership, is necessary so that all parties understand how these major decisions are made, which will affect perspectives on the acceptability of government and private sector cost-sharing involving hundreds of millions of dollars. The NGNP Project with private sector collaboration needs to establish an understanding of the rules of engagement up front. To avoid deployment delays going forward, the project needs a DOE-private sector agreed to process that avoids project work stops and starts that are inevitable in a sequential government procurement process such as described above. The Industry Alliance has recommended continuing design work in parallel with working out the specifics of the necessary public-private partnerships to execute the NGNP Project. The Alliance identifies that the primary risks are related to design and licensing, not technology maturation, and that these risks to the project are experienced early on. Furthermore, the Alliance asserts that a commercial business cannot practically take that level of risk.

The financial interest of any private industrial entity or team would lead to modest participation early in the project (defined as up to the point
Figure 10. In the future, a working partnership between DOE and Industry will lead to additional developments in areas like Fuel, as well as Engineering and Licensing areas needed to deploy the NGNP. 
of early final design, well into Phase 2 as described by DOE) rather than a 50-50 cost share. Furthermore, in order to mitigate design and licensing risks associated with the two main reactor design options (described briefly in Background of HTGRs section but in more detail in Appendix B on the provided CD), the Alliance's approach includes the completion of two preliminary designs, and then a subsequent decision whether to construct one or two designs. The current DOE approach calls for selection of a single reactor design following conceptual design.

\section{Cost Sharing (Alliance Approach)}

As stated above, the main difference between the two approaches lies in early cost sharing and timing and scope for the design. The Industrial Alliance maintains that most of the financial risk occurs early in the project where NGNP design and licensing risks and economics are still being fleshed out. They recommend that DOE bear closer to $85 \%$ of cost through early final design versus the 50-50 model outlined by DOE. Thereafter, the Industry Alliance would bear most of the cost such that when the first HTGR is deployed, the Industry Alliance members would have borne over $60 \%$ of the total remaining costs from 2010 forward. The Alliance asserts that this is consistent with the overall cost sharing approach defined in the 2005 EPAct. Additional details regarding the Alliance's approach are available in their Implementation Strategy (see CD provided).

\section{Conclusion}

Since the NGNP Project began, the pressures of environmental, economic, and industrial competitiveness have only increased the need to deploy such a technology. The technical, engineering, and licensing challenges are significant but not insurmountable. The initial needs of potential end users for the high temperature process heat generated by an HTGR have been identified and they look forward to its deployment in the early 2020s. The funding provided thus far has been strategically applied to accomplish that deployment by overcoming many technical and schedule risks, leading to significant technological advancements, partnerships, and solutions that are being brought to bear on the issues. Continued execution will result as existing partnerships are strengthened, new partnerships are established, and this application of nuclear energy becomes a key part of a larger energy portfolio that will enhance self-reliance, reduce the nation's carbon footprint, and strengthen the foundation of energy security for future generations.

Ultimately, the successful deployment of NGNP will hinge on the following:

- DOE and the NGNP Industry Alliance - or other qualified partner(s) - implementing a public-private partnership

- A commitment by the Administration, the Congress and the private sector to share the up-front risks

- Continuity of project funding over multiple years.

By taking immediate action to achieve these ends, DOE and industry can position the United States to realize the economic, environmental, and energy security benefits of HTGR technology. 
INL/EXT-09-17505

Revision 0 


\section{Appendix A}

\section{Research and Development Activities for the Next Generation Nuclear Plant Project}




\section{Appendix A \\ Research and Development Activities for the Next Generation Nuclear Plant Project}

The R\&D activities of the Next Generation Nuclear Plant (NGNP) project are organized into four major technical areas: (a) Fuel Development and Qualification, (b) Graphite Qualification, (c) High Temperature Materials Qualification, and (d) Design and Safety Methods Validation. This appendix discusses the objectives and progress of each area.

\section{Fuel Development and Qualification}

The High Temperature Gas Reactor (HTGR) concept is based on coated particle fuels (a coated particle is shown in the upper left of the figure below). Such fuels have been extensively studied around the world over the past four decades. Layers of carbon and silicon carbide surround the uranium core or kernel (the active part of the particle) thus forming tri-isotropic (TRISO)-coated particle fuel. The HTGR would contain billions of multilayered (TRISO)-coated particles. The material with the tiny particles of fuel distributed throughout is then shaped into either small cylinders called compacts or billiard-ball-sized spheres called pebbles (see figure). Rigorous control is applied at every step during the fabrication process to produce high-quality, very low-defect, fuel. Defect levels are typically on the order of one defect per 100,000 particles.

The TRISO layers provide robust protection for the nuclear material and outstanding retention of the radioactive material produced during fission. Extensive testing in Germany in the 1970s and 80s demonstrated that outstanding performance of high-quality, low-defect TRISO-coated particle fuels, under both normal operation and potential but highly improbable accident conditions, can be achieved. This outstanding performance, combined with the passive safety features of modern HTGRs, allows these reactors to be located close to industrial complexes where they can provide heat for the high temperature

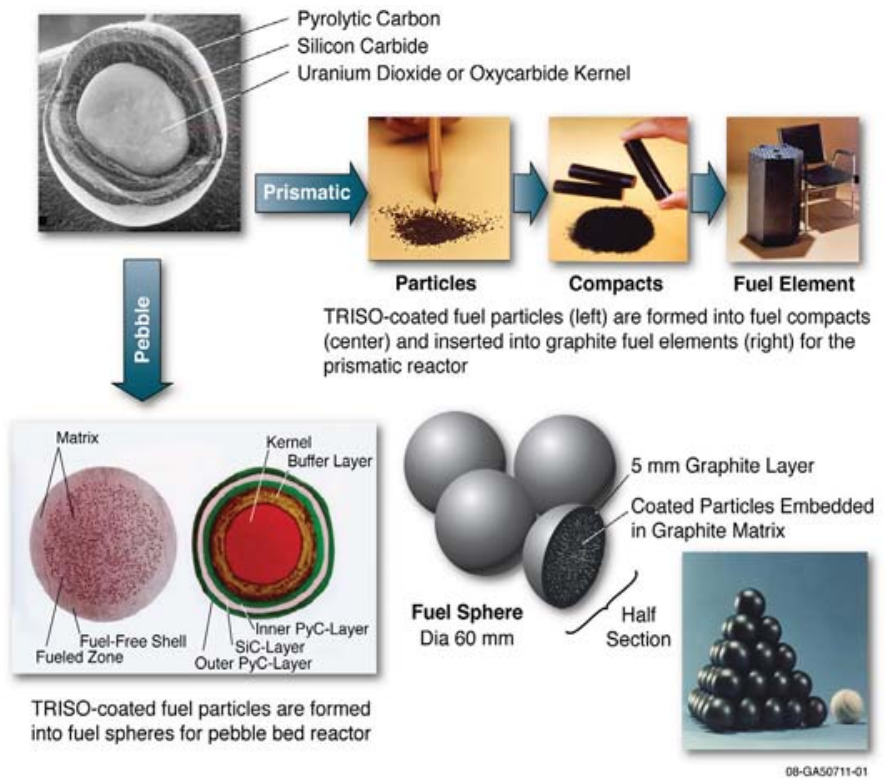

Figure A-1. TRISO - coated particle fuel are formed into spheres for a pebble bed HTGR and compacts for a prismatic HTGR. chemical processes and hydrogen for chemical and petrochemical industries, the major objective of the NGNP Project. Prior to the NGNP Project, the German testing was considered the "gold standard" of fuel performance around the world. Today, the NGNP Fuel Development and Qualification program is also achieving - , and in some cases exceeding - the high levels of fuel performance established by the Germans.

The objective of Fuel Development and Qualification program is to qualify TRISOcoated particle fuel for use in HTGRs being designed and licensed by the NGNP Project. TRISO-coated particles must be fabricated at industrial scale for use in qualification testing, as opposed to in small batches produced in a laboratory. The qualification testing consists of a variety of experiments and examinations that will allow an understanding of the behavior of TRISO-coated fuel under the radiation and temperature environment 
expected in an HTGR. The program also contains experiments to characterize the barriers to transport of fission products - the elements produced when uranium fissions - through the coated fuel particles, the graphite reactor core the primary coolant boundary and the reactor building under postulated accident conditions, (e.g., loss of helium flow, depressurization of the coolant system, water and/or air ingress). These experiments characterize fuel and fission product transport barriers performance under these conditions and provide validation of the technical basis for design methods (computer models) that are used in design and safety analyses of the plant including the calculation of radiological source terms.

At its inception, the Fuel Development and Qualification program had to re-establish the capability to fabricate and characterize TRISO-coated particle fuel in the U.S. after a 25-year hiatus. This was a significant effort that required the development of the fabrication processes and characterization approaches used in historical TRISO-coated fuel made in the 1970s and 80s. Many of the procedures and recipes used in the past were still available, but needed to be modernized to take advantage of improvements in measurement science over the past 25 -years. The result has been much more accurate and precise characterization of this fuel form. The fabrication effort has also deepened and significantly enhanced the team's understanding of how to fabricate TRISO fuel. In so doing, the team has actively moved TRISO fuel fabrication with its historical recipes to a disciplined scientific/engineering endeavor. While this approach takes more time and effort than simply using a recipe and accepting the results without knowing why the process works, the statistically significant understanding gained through this modernization will yield benefits during the licensing process with the Nuclear Regulatory Commission (NRC). The program is now fabricating high-quality, low-defect (about 1 defect in every 100,000 particles) TRISO-coated fuel particles at industrial scale, something that has never been accomplished in the U.S. before. Placing a U.S. fuel vendor in position to fabricate a high quality fuel with an understanding of enhanced fabrication for the NGNP establishes credibility with NRC by demonstrating that the historical results from the 1970s and 80 s are repeatable and have a sound technical basis.

The first fuel experiment, called AGR-1, has recently completed approximately three years of radiation exposure at the high temperatures expected under normal operation in a HTGR. About 300,000 TRISO fuel particles have been tested to a real level of energy utilization — called peak burnup — of 19\%, without a measureable indication of a single particle failure. These results are critical in demonstrating the superior performance capability of TRISO fuel and ultimately the HTGR concept. This level of burnup is about three times that of current light water reactors and double that achieved by the German gas reactor program in the 1980s. Work has also been underway to establish the capability to perform high temperature testing of this fuel at accident conditions (higher temperatures) to confirm robust safety performance of the fuel under highly unlikely but possible conditions. This testing will begin in late 2010 and provide critical qualified data on the safety basis of the fuel for licensing by the NRC.

The program has also spent significant effort developing a state-of-theart computer modeling and simulation capability to predict the behavior of TRISO fuel under the wide range of conditions anticipated in an HTGR. The model has been extensively compared against similar tools developed by international colleagues as part of an effort under the auspices of the International Atomic Energy Agency. The successful benchmarking of the fuel performance model has resulted in NRC's desire to use the model as part of their activities in confirming the results from other simulations.

\section{Graphite Qualification}

Graphite has been effectively used in the past as structural material for high temperature reactor cores. Historical grades of graphite and the

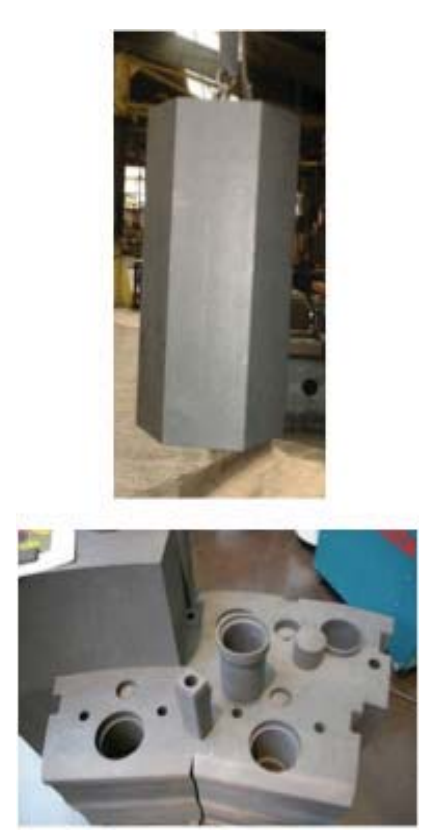

Figure A-2. Graphite core components. 
supply of raw feed stocks used in gas reactors no longer exist. The objective of the NGNP Graphite Qualification area is to demonstrate that modern grades of nuclear graphite made with current feedstock materials will perform at least as well as historical grades did. The program also has a goal to understand the complex behavior of graphite in the nuclear environment at a deeper scientific level relative to its overall performance for use in HTGRs. Thus, along with developing a qualification database of material properties for potential types of graphite for the HTGRs being developed by NGNP Project, the program is also establishing a science-based understanding of the fundamental mechanisms of irradiation behavior so it can predict how new graphite grades will behave in the future. Where practical, other types of graphite are being tested and analyzed to provide a baseline for comparison or to help understanding the material property changes of NGNP graphite types. In the longer term, the program plans to evaluate the influence of fabrication processes and different feedstock materials on graphite behavior so that extensive qualification efforts are not needed when feed stocks or improved fabrication methods are used to make graphite for future HTGRs after NGNP.

At the begninning of the graphite qualification research, significant effort went into establishing the analytical measurement laboratories required to perform the extensive characterization of nuclear graphite under consideration for HTGRs. This task consisted of procuring, setting-up, and calibrating state-of-theart analytical testing equipment and developing protocols and testing methods to make accurate, repeatable measurements on graphite, an ability well established for metals.

An extensive characterization effort is currently underway to establish the material properties before irradiation, on a series of large graphite chunks or blocks, called billets, that have been procured from two major graphite vendors (one in the U.S. and one in Europe). The first of six planned tests to evaluate the irradiation behavior of graphite under the radiation exposure levels and the high temperatures expected in an HTGR is underway. This test — the largest of its kind ever performed on nuclear graphite-will produce a large number of well-characterized irradiated samples. Tests are planned at specified temperatures, stress loading, and levels of radiation dosage that envelope the anticipated conditions for the HTGRs being developed by the NGNP Project. Extensive post-test examinations are also planned to understand the key material property changes caused by the irradiation exposure. These irradiation data and the as-fabricated material properties will be used to improve the detailed modeling and simulation tools currently being used to predict the structural response of graphite both inside a large block as well as throughout the whole core. The data from all characterization and modeling activities will be needed by the American Society of Mechanical Engineers (ASME) to certify the structural adequacy of graphite during the HTGR licensing process.

\section{High Temperature Materials Qualification}

The high outlet temperature (between 750 and $800^{\circ} \mathrm{C}$ depending on the application need) of an HTGR requires the development of high performance metallic alloys to transfer heat from the reactor to the process application. Because these alloys will contain the high-pressure helium used to cool the reactor, stringent requirements are imposed to ensure that this piping and the equipment through which the helium flows, called the pressure boundary, will maintain its integrity. Thus, the goal of High Temperature Materials Qualification program for NGNP is to obtain the performance data required to support the development of these high temperature components over the range of envisioned outlet temperatures. 


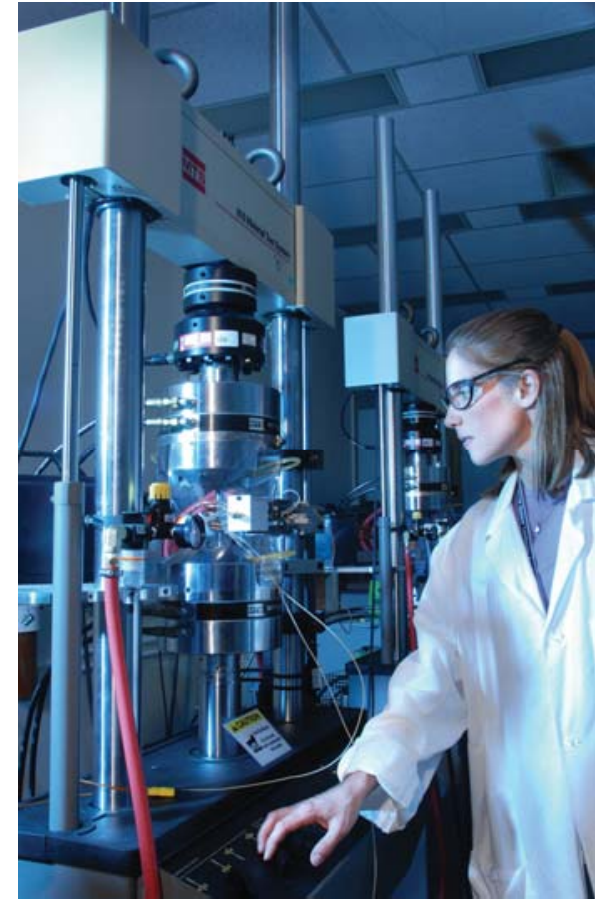

Figure A-3. High temperature material testing.
Production grade quantities of candidate high temperature alloys have been procured. State-of-the-art mechanical and environmental testing of the candidate high temperature metallic alloys is underway to understand its mechanical behavior at high temperatures and ensure that it does not degrade after long term exposure to low levels of moisture and other expected impurities in the helium coolant environment at the high temperatures expected in an HTGR. Extensive development of the testing equipment and its associated experimental procedures was required to modify traditional material test systems to accommodate the high temperatures necessary to obtain the accuracy and repeatability needed to qualify the alloys for use in a nuclear system like those found in HTGRs. The testing will cover a broad range of anticipated physical dimensions and structures to be used for the high temperature components including both thick and thin sections of the alloy, flat plate and tubes, as well as welded sections and other joints to ensure adequate structural performance and safety margins. A detailed characterization of each alloy is performed after each test to understand the underlying behavior at the microscopic scale that contributes to the measured mechanical behavior of the metal. All of the high temperature performance data generated in the testing will be needed to certify the structural adequacy of the high temperature metals

by the ASME via an established process, a part of the NGNP licensing process. As the design of the high temperature components in NGNP matures, R\&D is envisioned to establish techniques to inspect the metals that form the pressure boundary during operation of the reactor. Integrated testing of key high temperature components, or testing them with the connections and in the environment experienced as part of HTGR, will be needed to characterize the integrated behavior and validate the inspection techniques for use in NGNP.

\section{Design and Safety Methods Validation}

The goal of the NGNP Design and Safety Methods Validation program is to develop the experiments and data needed to validate modeling and simulation tools used to establish the design and safety of the HTGRs being developed by the NGNP Project. The program has participated with the NRC by using a wellestablished expert input process to rank important events that might occur during an accident. A best allocation of resources for safety-related $\mathrm{R} \& \mathrm{D}$ activities is developed based on the importance of the specific accident-related event to the overall safety of the HTGRs and the associated level of technical knowledge. Areas where the importance is high and the knowledge is low receive the greatest attention.

Based on this exercise, the NGNP Project and DOE are interacting with the NRC to jointly develop a set of large-scale experiments to provide safety-related
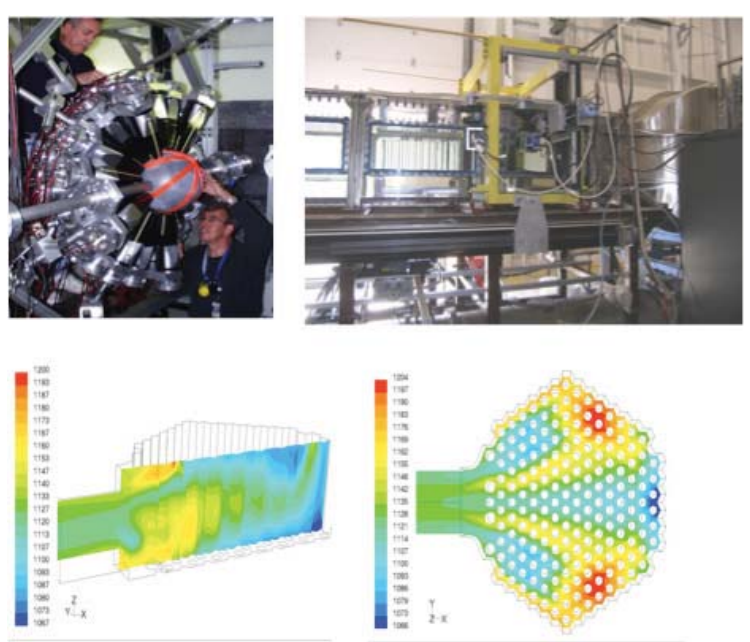

Figure A-4. Experiments and computer simulations used in HTGR design and safety analyses. 
data to validate modeling and simulation tools used to design and assess the safety of the HTGR design. This joint development effort avoids duplicative, costly experiments by the licensing applicant and the regulator. The DOE and NRC have also initiated a joint collaboration with the Japanese gas reactor team to obtain unique operational data from their operating high temperature gas test reactor to validate modeling and simulation tools that predict the behavior of the integrated reactor system. Assessments are currently underway by DOE, NRC, and NGNP personnel to technically evaluate other international capabilities that can be used to provide relevant safety data.

The program is also performing smaller scale experiments and developing enhanced computer models to better understand important phenomena at the basic physics or chemistry scale, to reduce uncertainties and improve design and safety margins. 


\section{Appendix B}

\section{State of the NGNP Technology and Technical Issues}




\section{Appendix B State of the NGNP Technology and Technical Issues}

This appendix addresses the current state of the NGNP technologies and the issues that will be addressed as the project goes forward.

\section{Technology Status}

\subsection{High Temperature Gas Reactor Technologies}

An HTGR is a graphite-moderated nuclear reactor cooled by helium, which heats to temperatures between 700 and $800^{\circ} \mathrm{C}$, enabling applications such as process heat to generate electricity or produce hydrogen for use in the chemical industry. Key characteristics of the HTGR concept are the use of helium as a coolant, graphite as the moderator of neutrons, and ceramic-coated particles as fuel. Helium is chemically inert and will not react under all conditions. The graphite core slows down the neutrons and provides high temperature strength and structural stability. The ceramic-coated fuel particles are extremely robust and retain the radioactive byproducts of the fission reaction under both normal and offnormal conditions.

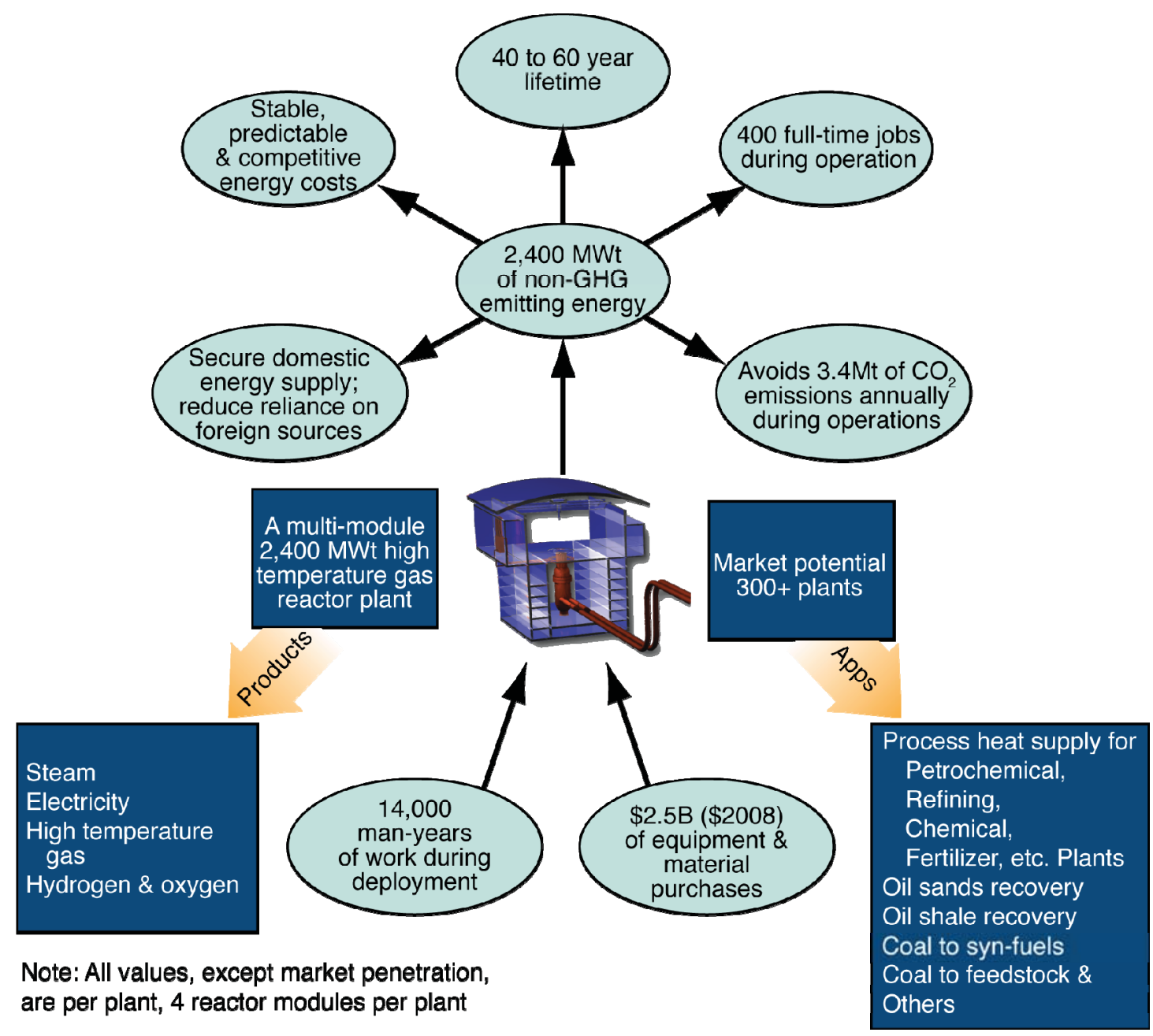

Figure B-1. The benefits of HTGR technologies. 
Two distinct reactor designs have been proposed: a pebble bed design and a prismatic block design. The specific plant configurations and operating conditions have evolved as the Project has progressed. However, these two basic designs have been maintained.

In the FY 2007 Pre-conceptual design work, the Westinghouse/PBMR(Pty) Team proposed a pebble bed reactor design patterned after the Demonstration Power Plant (DPP) being developed at the time by the South African PBMR(Pty) Ltd. The AREVA Team proposed a prismatic block reactor design patterned after the Antares design which has been in development for several years. General Atomics also proposed a prismatic block design similar to the Gas Turbine-Modular High temperature gas Reactor (GT-MHR) design that has been in development for several years and is the basis for a joint US-Russian venture.

Although these reactors are distinct in the design configurations they are both helium cooled and graphite moderated. They also use the same TRISO fuel technology. This fuel design was developed in Germany at the advent of high temperature gas reactor development in 1960s and has been the basis of these design reactors since that time. Variations of the fuel design were used in the AVR, Peach Bottom, Fort St.Vrain plants that operated in the 1960s-80s and are now in use in the Japanese High Temperature Test Reactor (HTTR) and the Chinese High Temperature Reactor. It is also the fuel design for the DPP, Antares, MHTGR, NPR, and GT-MHR design efforts that preceded the NGNP Project.

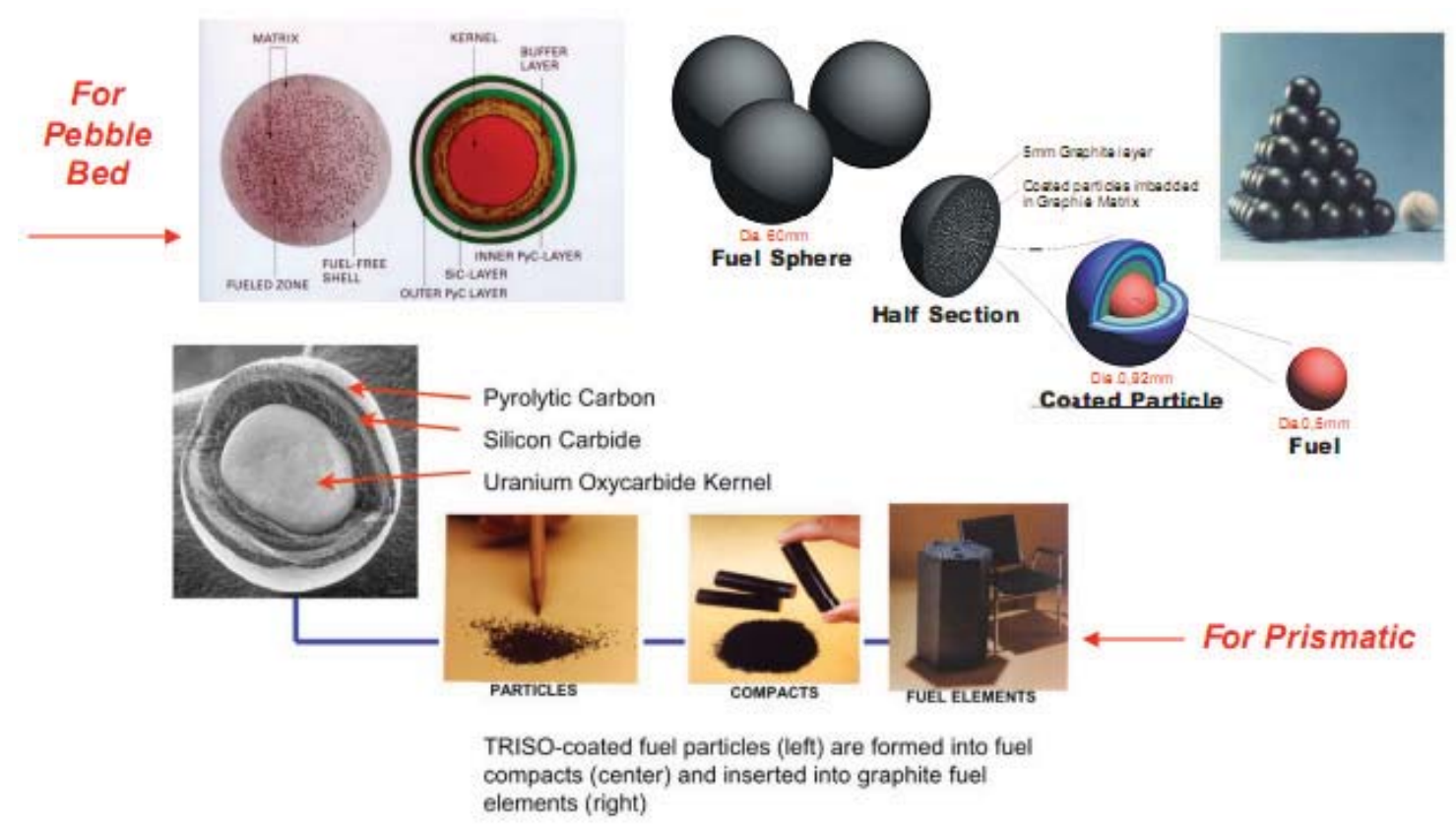

Figure B-2. TRISO fuel and pebble bed and prismatic block fuel element designs.

Figure B-2 shows the fuel design used in these reactors. The fuel is contained in a particle made up of several layers of three different materials; the use of three materials is the genesis of the TRISO designation. The center of the particle is formed by a uranium oxide or uranium oxycarbide kernel with a diameter in the range of 350 to 500 microns. When fully coated, the fuel particle is diameter is in the range 780 to 920 microns. The kernel contains the fissionable material. The kernel is surrounded by several layers of different carbonaceous materials. Each layer in the TRISO-coated fuel particle plays a role in fuel performance and fission product retention as follows: 


\begin{tabular}{|l|l|}
\hline \multicolumn{1}{|c|}{ Layer } & \multicolumn{1}{c|}{ Function } \\
\hline Oxide or Oxycarbide Fuel Kernel & $\begin{array}{l}\text { Contains fuel material; acts as a diffusion barrier } \\
\text { and chemical holdup of fission products and is the } \\
\text { structural base of the particle }\end{array}$ \\
\hline Buffer & $\begin{array}{l}\text { This is a relatively low density carbon material that } \\
\text { provides a void volume for gaseous fission product } \\
\text { holdup, accommodates kernel swelling and is a } \\
\text { sacrificial layer for fission fragments. }\end{array}$ \\
\hline Inner Pyrocarbon & $\begin{array}{l}\text { Pyrocarbon is a very dense material. The inner } \\
\text { layer provides a gas-tight coating, protects the } \\
\text { kernel from contamination, provides the first } \\
\text { diffusion barrier for metallic fission products and } \\
\text { reduces tensile stresses on the outer SiC layer }\end{array}$ \\
\hline SiC (silicon carbide) & $\begin{array}{l}\text { SiC is also a very dense and strong material that is } \\
\text { the primary metallic fission product diffusion } \\
\text { barrier and the primary pressure retaining layer in } \\
\text { the particle. }\end{array}$ \\
\hline Outer Pyrocarbon & $\begin{array}{l}\text { The outer layer provides the final gaseous and } \\
\text { metallic fission products diffusion barrier, reduces } \\
\text { tensile stresses on the SiC layer, provides a } \\
\text { bonding surface for overcoating, (e.g., with a dense } \\
\text { hard carbonaceous material) or matrix material, } \\
\text { (e.g., as embedded in the reactor fuel element). }\end{array}$ \\
\hline
\end{tabular}

The nuclear core in each reactor design contains millions of these particles in fuel elements of differing configurations. As shown in Figure B-2, in the pebble bed design the fuel particles are contained within a spherical carbon matrix about the size of a billiard ball. The exterior of the sphere is coated with a dense and hard carbonaceous material to resist abrasion. The spheres are referred to as pebbles in that reactor concept. The core of the pebble bed reactor contains several thousand pebbles.

In the prismatic block design the fuel elements are in the form of hexagonal graphite blocks that contain several parallel longitudinal holes in which are stacked several fuel compacts. Many fuel particles are embedded within the fuel compacts. The blocks are stacked on end and extend in two to three annular layers to form the reactor core (see Figure B-7). The core contains several thousand fuel compacts. The fuel element blocks also contain empty longitudinal parallel holes for coolant flow.

\subsubsection{The Pebble Bed Reactor}

In the pre-conceptual design work, the Westinghouse/PBMR (Pty) Ltd. Team proposed an annular core pebble bed reactor design shown in Figure B-3. As is typical with these HTGR designs the core is surrounded by thick graphite layers that act to support sustained nuclear fission and containment of the neutrons produced from fission. These are the side, top, bottom and center reflectors shown in the figure. The nuclear reaction is controlled with control rods that penetrate the side reflectors from the top. The pebbles make up the core that is located within the annulus formed by the side reflector and the center reflector. The core and reflectors are contained within a core barrel. The reactor vessel is the primary structural and pressure retaining component of the reactor. Lower temperature helium coolant enters the 
vessel at the top, flows down through the core and exits at the bottom through the inner pipe of a dual pipe configuration. The annulus between the inner and outer vessel wall contains a small flow of lower temperature helium as part of the insulation system for the reactor outlet piping and the vessel. This helium flows up through an annulus between the core barrel and the reactor pressure vessel and rejoins the principal core inlet helium in the upper plenum.

The pebble bed reactor is refueled on-line. The fuel bearing pebbles enter the annulus of the core through three lines offset by $120^{\circ}$ at the top of the vessel. Over a period of about 6 months each pebble travels down the core and exits from the bottom of the vessel. Each pebble is then examined in the plant fuel handling system to determine if it has reached its burnup limit or is damaged. In these cases it is removed from the system and a fresh pebble is inserted. Otherwise the pebble is returned for another pass through the core. A typical pebble will make several passes through the core.

This annular core pebble bed design is based on the South African PBMR (Pty) Ltd DPP design which features a direct cycle gas turbine as shown in Figure B-4. In this design the primary coolant feeds a Brayton cycle gas turbine at a reactor outlet temperature of $900^{\circ} \mathrm{C}$ to $950^{\circ} \mathrm{C}$. This design is used primarily for electricity production, although waste heat from the recuperators can be used for lower temperature applications.

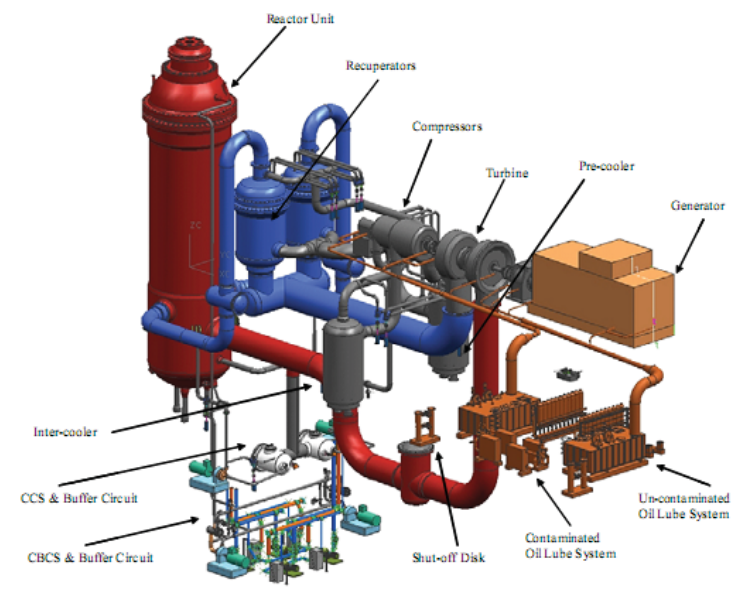

Figure B-4 - PBMR (Pty) Demonstration Power Plant (DPP) Design

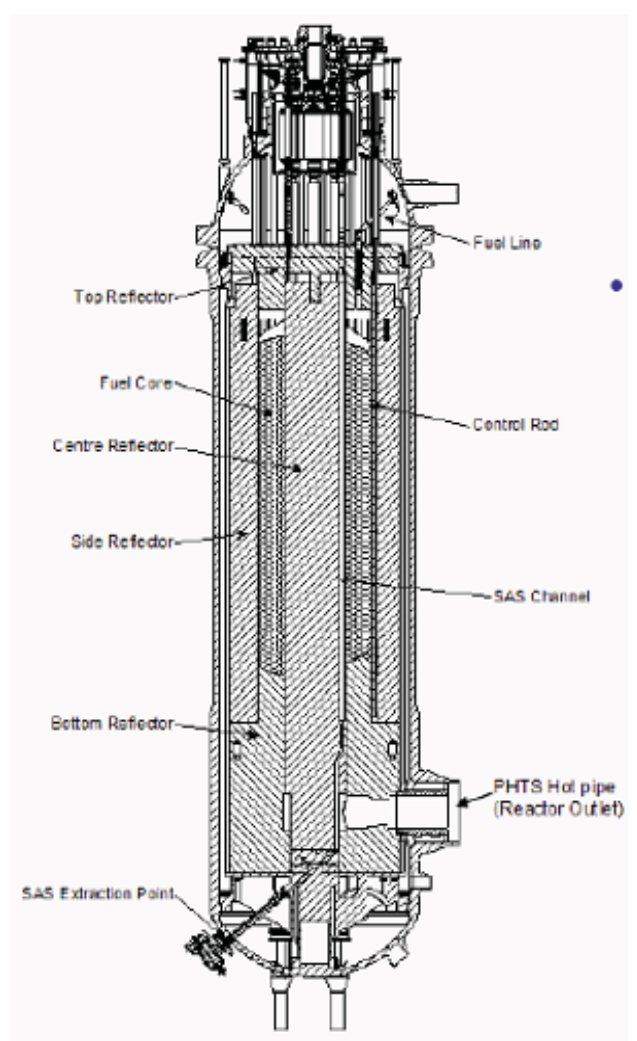

Figure B-3 - Pebble Bed Reactor with Annular Core

The heat transport system and balance of plant proposed by the Westinghouse team in FY 2007 for the NGNP demonstration plant included two intermediate heat exchangers in series in the primary loop supplying energy to a secondary helium loop that supplied a steam generator and the hydrogen process, see Figure B-5. The steam generator supplied a steam turbine generator for the production of electricity. 
The hybrid-sulfur process was proposed for hydrogen production; the hot gas supplying the heat necessary to support the sulfuric acid decomposition component of the process and electricity supplying the electrolysis components of the process. Excess electricity was to be sold on the local grid.

As a result of the work performed on assessing the needs of potential end users in FY 2008 and FY 2009 and changes in their design philosophy in FY 2009, the Westinghouse/PBMR (Pty) Ltd Team revised the core design and the plant configuration for the NGNP Plant to that shown in Figure B-6.

In the revised pebble bed core design the center reflector has been removed producing a cylindrical rather than the original annular pebble bed configuration. The power rating of this reactor design is in the range of $200 \mathrm{MWt}$ to 250 MWt compared with the $500 \mathrm{MWt}$ power rating of the annular core design. The reactor outlet temperature will be in the range $700^{\circ} \mathrm{C}$ to $750^{\circ} \mathrm{C}$. The

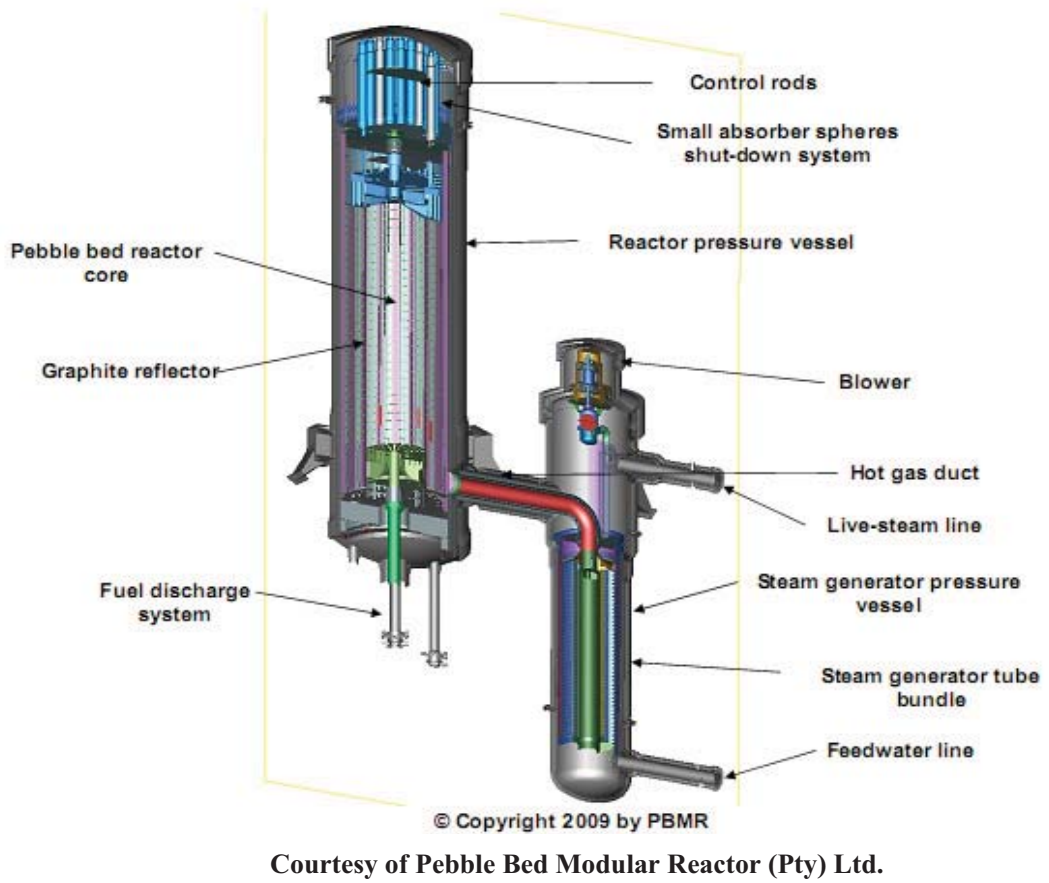

Figure B-6 - Current PBMR Core Design and Plant Configuration

Westinghouse/PBMR (Pty) Ltd

Team cites the ability to bring this design to market faster with lower risk and on a more competitive basis than the larger plant design as the principal reasons for proposing this design. The heat transport system includes a steam generator in the primary helium loop which will supply steam to a conventional Rankine steam turbine generator. The plant is intended to serve co-located processes requiring steam and electricity.

\subsubsection{The Prismatic Block Reactor}

General Atomics and AREVA propose prismatic block reactor designs for the NGNP Plant. A typical design is shown in Figure B-7. As discussed above, the fuel elements in this design are hexagonal shaped blocks that contain fuel compacts in which are distributed the fuel particles. The blocks are stacked (10 blocks high) and arranged in two to three annular rings depending on the power level of the reactor. In the FY 2007 pre-conceptual design work, $550 \mathrm{MWt}$ to $600 \mathrm{MWt}$ reactor designs with reactor outlet temperature of $900^{\circ} \mathrm{C}$ to $950^{\circ} \mathrm{C}$ were proposed by both suppliers. The AREVA reactor design was derived from the Antares plant, Figure B-8. The Antares plant is designed for electricity production and includes an indirect Brayton cycle gas turbine in a horizontal configuration fed from the heat exchanger shown in the figure. The AREVA proposal for the NGNP Plant was similar to Antares including an indirect configuration supplying a combined cycle turbine configuration for electricity production with a parallel loop supplying high temperature gas to either a prototype hydrogen production facility as shown in Figure B-9. AREVA did not have design of the hydrogen process in their pre-conceptual design scope. They briefly evaluated high temperature steam electrolysis at the Project request and used the characteristics of the sulfur-iodine process in developing the production capacity and economics of an nth-of-a-kind (those following NGNP, which is the first-of-a-kind) HTGR based hydrogen plant. 


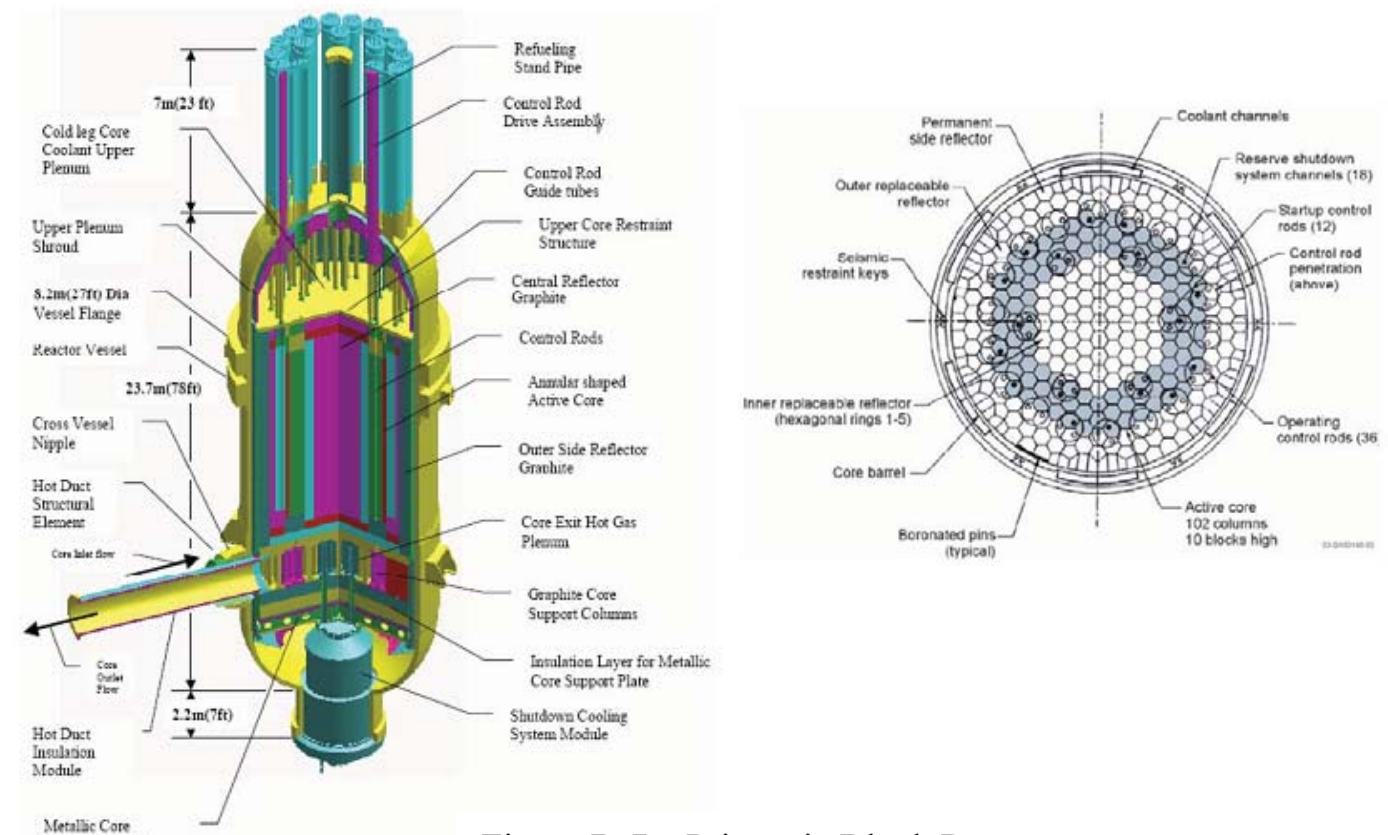

Figure B-7 - Prismatic Block Reactor

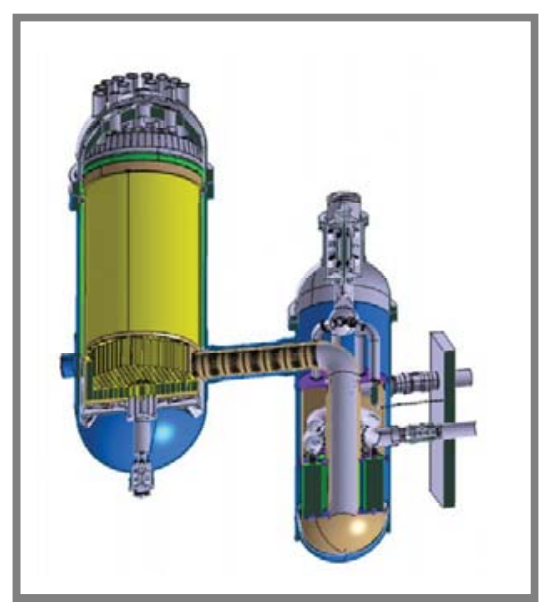

Figure B-8 - AREVA Antares

The General Atomics reactor design is derived from the GTMHR plant, Figure B-10. This includes a direct Brayton cycle gas turbine in a vertical configuration to produce electricity as shown in the left loop. For the NGNP plant General Atomics added a second parallel loop (shown on the right in Figure B-11) supplying a compact intermediate heat exchanger that in turn supplies heat to a prototype sulfur-iodine hydrogen production facility.

In FY 2008 and FY 2009, AREVA and General Atomics revised their plant operating conditions and configurations as a result of the interactions with the potential end users. Both of these Suppliers are currently proposing plant configurations that have a steam generator in the primary loop supplying both process steam and a conventional Rankine steam turbine cycle as shown in Figure B-11. Two reactor power levels; $350 \mathrm{MWt}$ and $600 \mathrm{MWt}$, are being considered with reactor outlet temperatures in the $750^{\circ} \mathrm{C}$ to $800^{\circ} \mathrm{C}$ range. The $350 \mathrm{MWt}$ design is based on the Modular High Temperature Gas Reactor (MHTGR) design that DOE / General Atomics developed in the late 1980s. Having two different power levels could provide flexibility in applying the technology in multiple module configurations to satisfy variations in demand and availability requirements. AREVA and General Atomics judge that these operating conditions and plant configuration reduce technical risks and support bringing the HTGR technology to market sooner than the higher temperature design. 


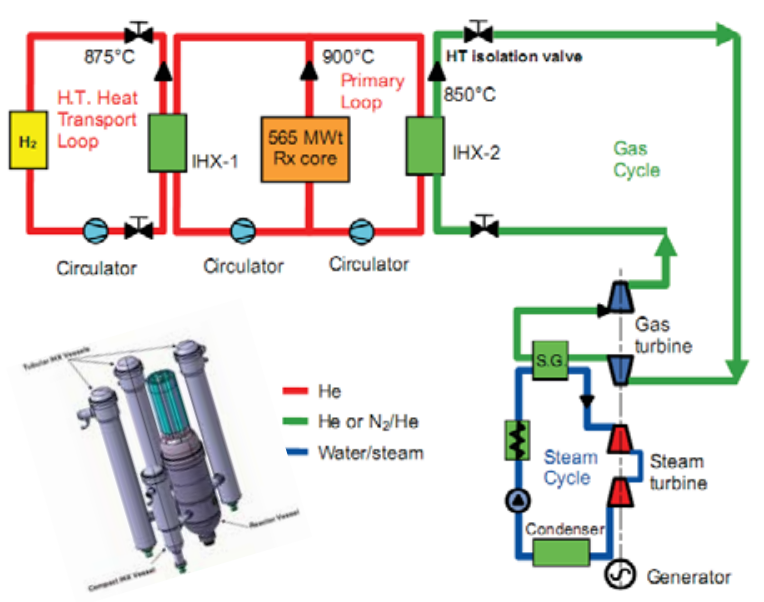

Figure B-9 - AREVA Original Proposed NGNP Configuration

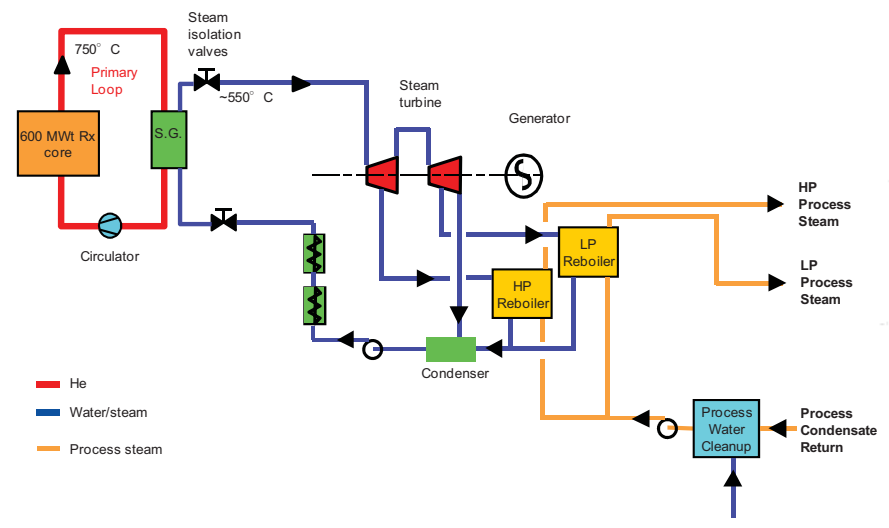

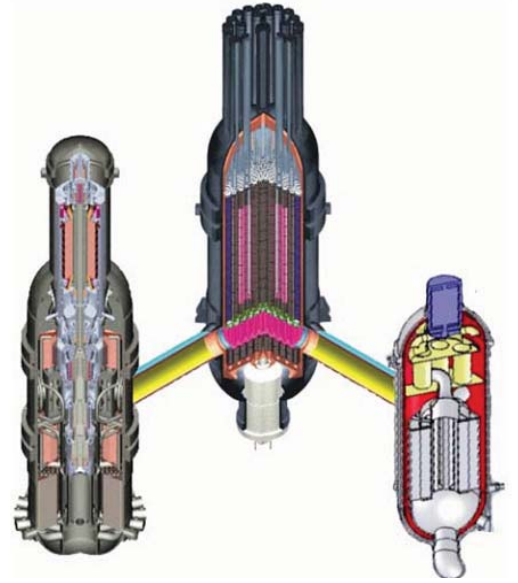

Figure B-10 - General Atomics Original Proposed NGNP Configuration

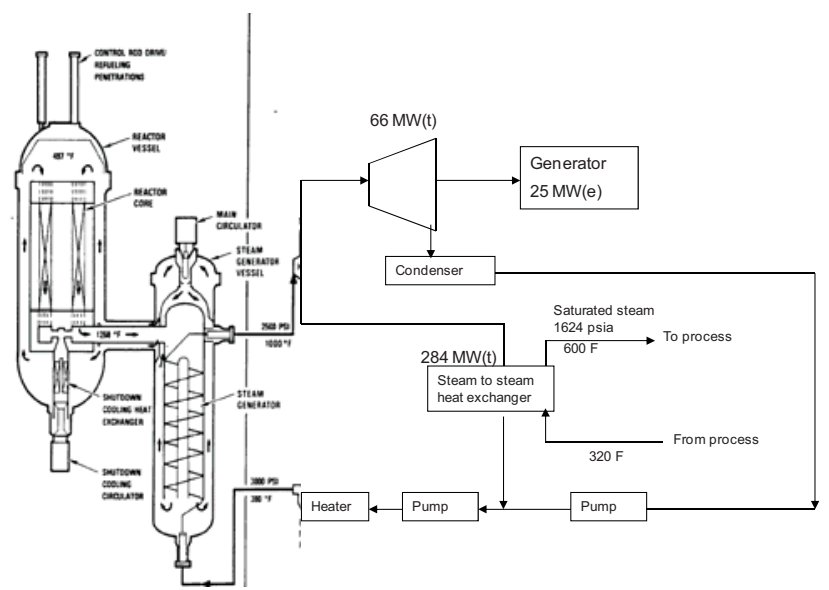

Figure B-11 - AREVA (left) and General Atomics (right) Current Proposed HTGR Plant Configurations

\subsection{Hydrogen Plant Design}

The EPAct charged the DOE with developing the high temperature reactor for the purposes of supporting the production of electricity and/or hydrogen. The pre-conceptual design work performed in FY 2007 provided designs meeting this objective. In FY 2008 and FY 2009 investigations of potential end-user energy needs re-directed the supplier focus away from higher reactor temperatures to lower temperature cycle producing only steam. However, expanded discussions with potential end-users in the petrochemical and fertilizer industries indicate a need for clean and economic production of hydrogen. In FY 2009, an independent review team (IRT) evaluation was performed of the candidate processes for hydrogen production that can be efficiently supported by the HTGR technology. This evaluation was performed by a panel of experts in the field that reviewed the three processes that have been the focus of the Nuclear Hydrogen Imitative (NHI) and NGNP Programs, (e.g., high temperature steam electrolysis, hybrid-sulfur \& sulfur-iodine as shown in Figure B-12) as well as others. 


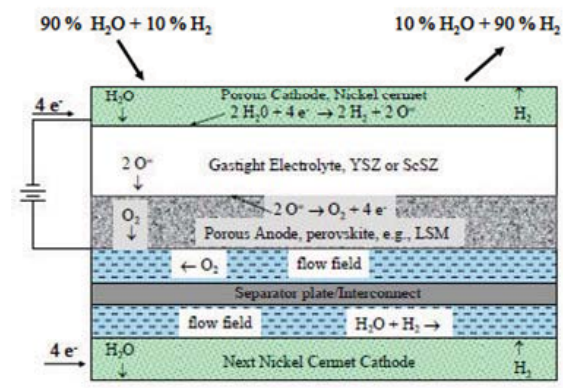

High Temperature Electrolysis
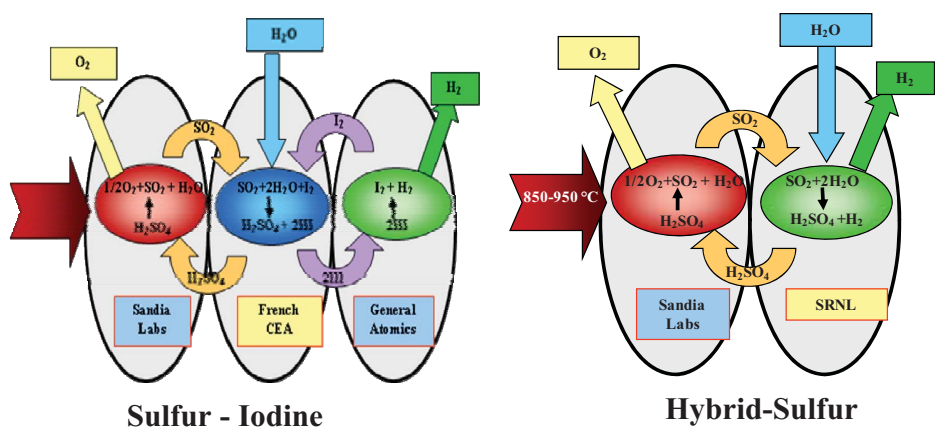

Figure B-12 - Hydrogen Production Processes

This panel concluded:

"DOE-NE should focus on the continued development of HTSE [high temperature steam electrolysis] as the leading candidate for integration with NGNP in 2021. This conclusion is based upon the IRT judgment that HTSE has the highest probability of meeting the down-selection criteria described in the report, including efficient production of hydrogen at NGNP conditions"

With respect to the other two technologies the panel recommended that if resources are limited and both technologies cannot be pursued:

"DOE should consider as a minimum giving higher priority in any $R \& D$ to topics that benefit both of these technologies such as continued development and modeling of the sulfuric acid decomposer."

The Project has been continuing to support these programs in concert with this recommendation.

All of the hydrogen production processes considered for coupling with the HTGR have optimum efficiencies in the $850^{\circ} \mathrm{C}$ to $950^{\circ} \mathrm{C}$ range. As noted, the current proposed operating conditions for NGNP are lower than this range. The efficiency of the HTSE process is not as adversely affected by a lower temperature as the other processes as shown in Figure B-13 [Thermal Water Splitting Efficiencies, from Yildiz and Kazimi (MIT)]. There are also mechanisms, (e.g., recuperation using waste heat in the cells) to raise the steam temperature locally. The HTSE program has made recent breakthroughs in extending the life of the electrolyzer cells supporting expectations that this will be a viable approach for hydrogen production using the HTGR.

With the current emphasis by the suppliers on supplying only steam and electricity in the first-of-a-

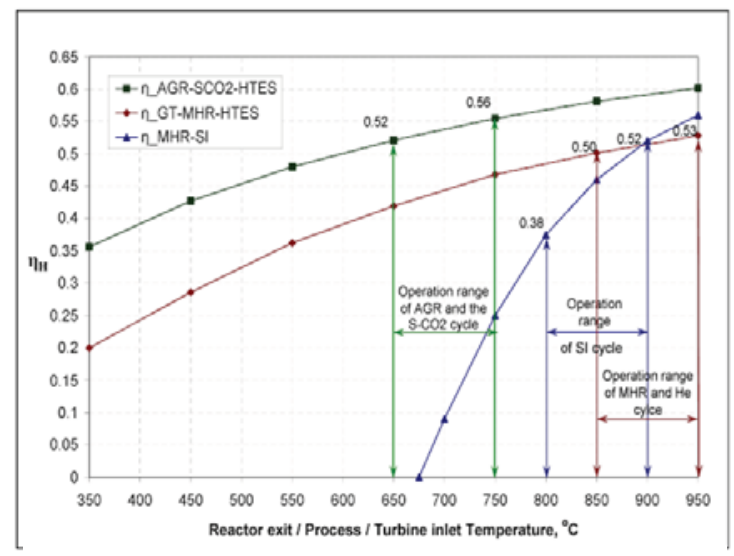

1 Figure B-13-Comparison of the thermal to hydrogen efficiency of the HTSE and SI hydrogen production processes as a function of temperature kind (FOAK) plant, they have recommended that the Project demonstrate a prototype of the hydrogen process using the large scale Component Test Capability rather than as part of the FOAK plant configuration. This recommendation has been factored into the current strategy for completing the Project. This demonstration would occur in the same time frame as the initial operation of the FOAK NGNP Plant, (i.e., by the end of 2021). 


\section{Technical Issues and Tasks}

\subsection{Issues Affecting Plant Design}

The following sections summarize a number of issues affecting the design of the HTGR plant that need to be addressed and resolved early in the design process, (e.g., during the initial phases of conceptual design). The resolution of these issues will affect the cost of the plant, the schedule for completion, the range of commercial applications to which the plant can be applied, the approach and scope of licensing by the NRC, and the economics of the HTGR application. Work to date has addressed some of these issues on a general basis, without a conceptual design to anchor the analyses. Completion of this Project in a time frame that is of interest and use to industry (e.g., initial plant operation in 2021 to 2022) requires that the final configurations and operating conditions for the plants be established and the issues listed in the following sections begin to be addressed and resolved within FY 2010 to FY 2011. This schedule is necessary so that design, licensing, cost, schedule and economic factors can be established with sufficient confidence to confirm HTGR technology technical, licensing, and economic viability.

\subsubsection{Reference Configuration / Operating Conditions / Plant Level Analyses}

Prior to conceptual design there was no established reference configuration that would meet initial industry needs. There was also no full definition of the operating conditions (power level, reactor outlet and inlet temperatures, etc.). It is anticipated that these will be developed during conceptual design.

As noted, it is anticipated (on the basis of Senior Advisory Group recommendations) that the Project will go forward with development of module configurations that include a steam generator in the primary loop. The steam generator will supply steam to a steam turbine generator(s) for the production of electricity and steam to an industrial process. If required by the application, the module configuration may also include a gas-to-gas intermediate heat exchanger for supply of high temperature gas to the industrial process. Two nuclear heat supply systems (NHSS) will be developed; one for the pebble bed and the other for the prismatic block reactor designs. The NHSS will operate with a reactor outlet temperature in the range $700^{\circ} \mathrm{C}$ to $800^{\circ} \mathrm{C}$. NHSS power levels of $200 \mathrm{MWt}$ (pebble bed), $350 \mathrm{MWt}$ and $600 \mathrm{MWt}$ (both of the prismatic block design) will be provided. A typical HTGR plant will supply a colocated industrial process and will comprise several modules to meet its energy demands with essentially $100 \%$ availability.

These assumed configurations and operating conditions currently inform the development of licensing white papers, discussions with the NRC and the R\&D programs. Complete plant level steady state and transient analyses of the specific NHSS and plant configurations are also required, however, to ensure that these activities are fully informed, and to establish design margins, for normal, abnormal and accident conditions. Since these licensing and R\&D activities are currently progressing it is necessary that the design activities required to confirm the final configurations of the NGNP Plant and to complete these analyses be initiated as soon as possible.

\subsubsection{Technology Readiness Levels of PASSCs}

The NGNP Project Risk Management Program has developed and implemented a technology development roadmap (TDRM) process that: (1) establishes the technology readiness level (TRL) of each critical $^{1}$ plant area, system, sub-system and component (PASSC), and (2) develops the necessary effort to

\footnotetext{
${ }^{1}$ Critical PASSCs are defined as those components that are not commercially available or have not been proven in relevant industry environments, at appropriate scale, or fully integrated with other components.
} 
achieve the TRL required to have confidence in the performance of the PASSC when installed in the plant. The development of design data needs during the pre-conceptual design work in FY 2007 and refinement of these needs in FY 2008 and FY 2009, combined with development of the TDRM for the HTGR, identified the areas listed in Table 1 as specific areas requiring technical development, both generically as well as design-specific (as shown by "Supplier" in the table). The TDRM defines the specific efforts required to progress the TRL of the areas summarized in Table B-1. The TRL of every developmental component, the status of the necessary work scope to advance TRLs and the summary tables are maintained by the Risk Management Program in coordination with the Supplier Teams.

Although Table B-1 identifies specific development effort required by reactor type, close examination of the table reveals that the fundamental development requirements are common across all reactor designs. There is no clear distinguishing characteristic or developmental requirement in any of the designs proposed to date in the Project that favors one design over the other. This fact supports continuing the development of both design concepts (e.g., prismatic block and pebble bed designs). The following issues, therefore, apply to both reactor types.

\subsubsection{Completion of R\&D Qualification Programs}

The NGNP R\&D programs are principally focused on confirmation of critical material performance and the ability of commercial processes to produce components consistently within specification requirements, (e.g., confirming that the fuel and graphite fabrication processes produce material that perform as assumed (or better) in the design analyses of the plant). There are four formal programs that cover Fuel, Graphite, High Temperature Materials and confirmation of Analytic Methods. There are program plans for each area containing detailed plans. This work is focused on ensuring that these are validated to meet the technical and licensing requirements for the technology. These are necessary and sufficient for design needs.

Two areas of specific importance in addressing technical and licensing needs are:

- Confirming the attenuation factors in transport of fission products (radionuclides) through each barrier to release to the environment in support of source term and worker and offsite dose calculations for normal, abnormal and accident conditions.

- Developing the mechanisms and the effects of air and water ingress to the core under accident conditions on the radionuclide source term and integrity of the core.

These are major efforts within the NGNP Project R\&D Program that are needed to confirm the source terms and calculated offsite doses under all conditions. A premise of the HTGR safety basis is that calculated off-site dose under all postulated normal, abnormal and accident conditions, including beyond design basis conditions, are sufficiently low to eliminate evacuation and sheltering requirements of emergency planning. Reduced emergency planning requirements is an essential element in applying the HTGR technology to co-locating the plant for supply of energy to a wide range of industrial and commercial applications. Completion of these evaluations is necessary to support the Plant Level Analyses discussed in a prior section. Conceptual design work needs to be completed to develop the specific design configuration and operating conditions of the plants to the level sufficient to inform these evaluations.

\subsubsection{Development of Analysis Codes}

Many of the computer codes used by the Suppliers were developed several years ago. These include thermal-hydraulic, computation fluid dynamics, physics, fission product transport and other codes. These need to be updated to reflect experimental and development work completed since these codes were developed and to run on modern computer platforms. Much of this work will be done by the Suppliers 


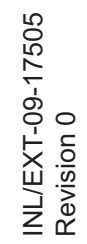

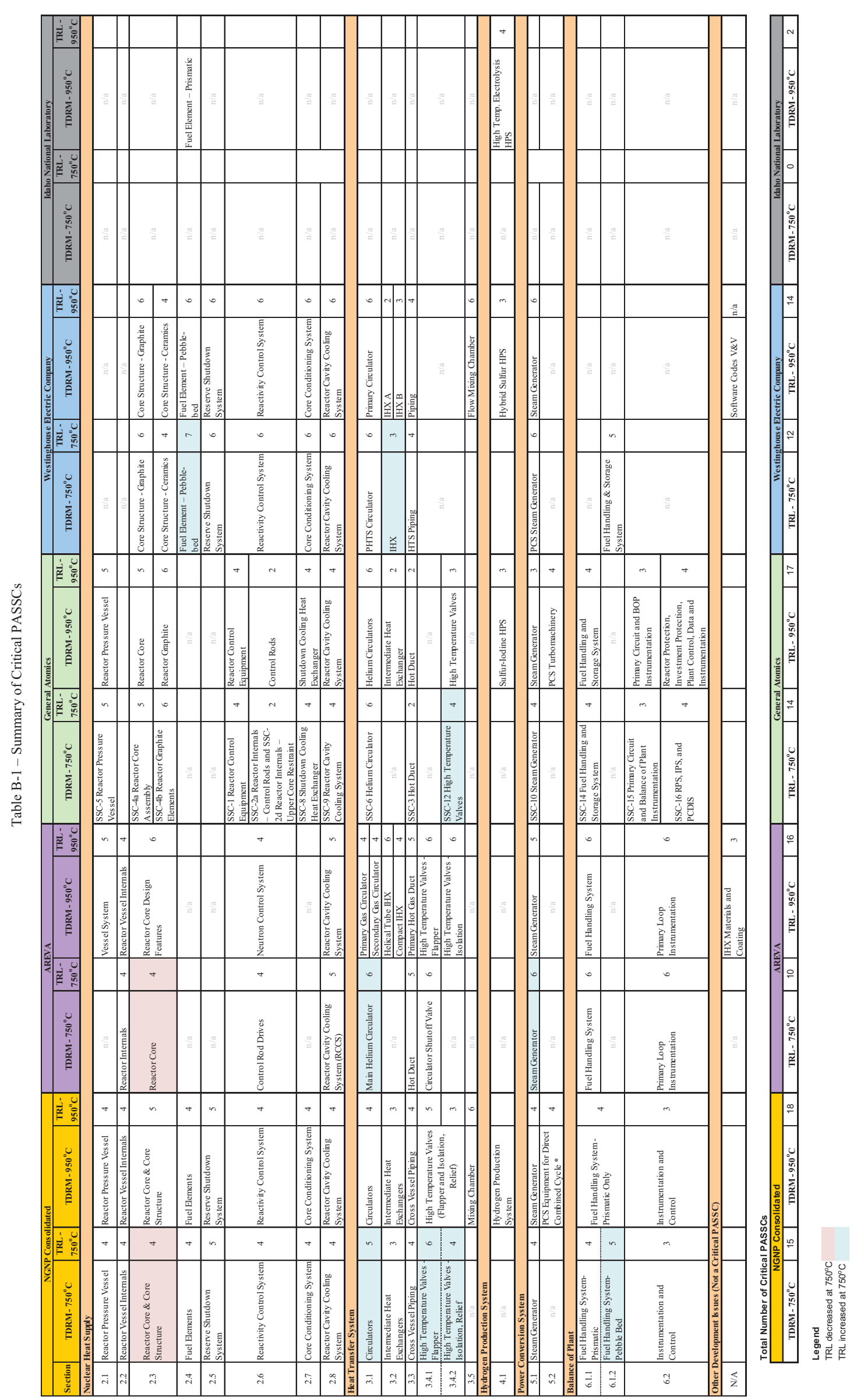


but will be supported by the Project R\&D Program for production of experimental data and code validation.

\subsubsection{Supply of Fuel and Graphite}

Significant deployment of the HTGR technology in the commercial sector will require a stable, economic and reliable source of reactor fuel and graphite. To the date of this writing there has been little work done, other than initiating confirmation of fabrication processes and development of specifications, to ensure that this infrastructure is developed and available. This is an area requiring attention as the design of the FOAK module progresses. The expectation is that this FOAK module(s) will be followed shortly by commissioning of sister modules to form a commercially viable plant(s). This and continued deployment of these modules and plants in other applications require more capacity than currently projected to be available for fuel and graphite supply.

\subsubsection{ASME / ASTM Code Case Development}

Code cases and specifications are required for use of graphite in the NHSS. The Project is supporting committees in ASME and ASTM for these purposes. This effort needs to progress expeditiously to support licensing activities and material supply.

The reduction in reactor outlet temperature has reduced the immediate need to develop new code cases for candidate materials considered for the higher reactor outlet temperatures, (e.g., P91). There is still need to update some code cases for existing ASME materials, (e.g., Inconel ${ }^{\circledR} 617$, Incoloy ${ }^{\circledR} 800 \mathrm{H}$ ) to extend the covered operating temperatures to the ranges anticipated for the current HTGR designs. The Project has been working with the ASME and the ASME ST-LLC to conduct the necessary development work and develop the material required for update of the codes. This work must proceed on a time line that supports the design and licensing schedule. Effort should also progress on development of material necessary for submittal of new code cases for the higher temperature materials and for ceramic materials (see item 2.1.7) that are required for operating the HTGR in the higher temperature ranges.

\subsubsection{Infrastructure for Development and Supply of Equipment and Materials}

The wide ranging deployment of this technology requires a reliable supply of equipment and materials for plant construction and maintenance. These include:

\section{Large vessels}

Large vessels, such as the reactor pressure vessel, will be fabricated vessels which will need supplies of plate, forgings, plate forming and rolling facilities, qualified welding procedures, etc. Currently, there are no such facilities in the US and the offshore facilities are becoming backed up with foreign nuclear plant development. A US source of steel, large scale forging and forming facilities is required not only for HTGR deployment but for the future of all large scale steel fabrication in the US, (e.g., LWR deployments, petrochemical and refining industries). It is understood that DOE-NE is initiating a task to work with U.S. steel suppliers to address this issue primarily to support light water reactor development. This needs to be pursued on a broader scope to support the full range of large vessel needs.

\section{Helium Circulators}

Most of the larger capacity gas circulators used in current gas reactors (e.g, in the UK) are in lower temperature, $\mathrm{CO}_{2}$ fluid systems. Suppliers of similar and larger sized circulators for operation in helium must be identified and developed. 


\section{Ceramics}

There are certain areas within the NHSS where metallics may not be acceptable due to high environmental temperatures during normal, abnormal and accident conditions. Control Rod sleeves are an example. Ceramics have been identified as a possible material for use in these locations. These materials require development and identification of qualified suppliers. There are currently no plans in either the NGNP R\&D programs or the planning discussed to-date by the nuclear system suppliers for such a development program.

\section{Heat Exchange Equipment}

The heat transport system will include some combination of gas to gas heat exchangers and steam generators in the primary loop depending on the form of energy required by the process. The steam generator designs will follow closely the designs and experience in prior applications of the gas reactor, (e.g., spiral tube configurations such as used in Fort St. Vrain in Colorado, US, and AVR in Germany).

Work to-date on gas-to-gas heat exchangers has focused on use of compact heat exchangers of the printed circuit, plate-fin, welded plate and other designs. There is no prior operating experience with these designs in gas reactor applications. Development and confirmation of performance and identification of reliable suppliers are required for these heat exchangers. There is currently a low-level program being supported by the NGNP Project. This program needs to be expanded and supported in order to ensure the availability of reliable gas-to-gas heat exchangers for deployment in the FOAK or sister plants.

\section{Instrumentation and Controls (I\&C)}

The high operating temperature of the HTGR and the use of concentric annular piping for the hot and cold legs of the primary coolant system design present challenges for measurement of neutron flux, coolant temperatures and, if required, coolant flow. The plant safety and non-safety instrumentation and control systems will be configured with the latest digital designs; plant control elements, (e.g., valve operator controllers) will also be digitally configured. Specific design work to establish the requirements on I\&C for safety and non-safety monitoring and control of the plant is required as part of conceptual design. Development work may be required depending on the results of this design work in specific instrument areas, (e.g., temperature and/or flow measurement). Developmental control schemes may also be required depending on plant configuration, (e.g., coordinated control of primary and secondary circulators to ensure that pressure differential limits are not exceeded across the heat exchange elements of an intermediate gas-to-gas heat exchanger under normal, abnormal and accident conditions).

\section{Valves}

The application of valves in the NHSS provides contrasts between the ability to use standard valve designs and the need to develop new or upgrade existing valve designs:

The configuration of the primary coolant system in a gas reactor does not lend itself to the positioning of isolation or maintenance valves in that system. This is also the case in the majority of the LWR plant designs. The locations where valves will be used in the NHSS of the HTGR include:

- $\quad$ Primary Coolant Relief and Safety Valves - these function to ensure that the primary coolant pressure remains below design limits. This is an application where an existing relief or safety valve design may not be adequate. The principal functions of these valves are to achieve reliable leak tightness during normal operation, consistent lifting at the set pressures, and required accumulation and blowdown during operation. The designs of these valves will reflect standard design practice and experience in prior gas reactor operation. The principal areas of developmental for these valves may include: 
- Operation at higher temperatures particularly as the HTGR technology evolves to higher reactor outlet and inlet temperatures

- The ability to perform to specification when relieving either helium or a steam-helium mixture in the event of a tube leak in those configurations that include a steam generator in the primary loop.

- Circulator Discharge Check Valve - this valve prevents backflow through the circulator during operation of the shutdown cooling system, during single circulator operation in a dual parallel circulator configuration or if there are parallel primary loops, (e.g., if the reactor is supplying more than one heat exchange components) and one loop is not in service. These are standard valve designs that are provided by the circulator supplier. The potential need for development and confirmation of performance stems from operation at temperatures and flowrates higher than in the prior experience base. The functioning of these valves would be verified in functional testing of the associated circulators.

- $\quad$ Steam and Feedwater Isolation Valves - these are supplied on the steam leads of the steam generator and the feedwater inlets of the steam generator. It is anticipated that an HTGR steam generator would operate at typical fossil plant conditions, (e.g., $2450 \mathrm{psig}, 1000^{\circ} \mathrm{F}$ outlet steam conditions).

Accordingly, these will be standard valves that should not require substantive development. These valves would function to isolate the steam generator in the event of a tube leak.

- $\quad$ Steam Generator Dump Valves - these may be supplied, depending on the results of analyses of the significance of a steam generator tube leak, to dump the water from the steam generator to a storage tank in the event of a tube leak. These will need to operate rapidly and have the capacity for rapid blowdown of two phase flow to the tank. The control of these valves will need to ensure that there is no backflow of helium from the primary side into the steam generator and these valves to prevent contamination and potential water hammer in the system. It is anticipated that the required characteristics of these valves can be met by available designs and not require significant development. Functional testing of an engineering scale dump system and its controls may be required to verify performance.

- Maintenance Isolation Valves - the need for and design of these valves has not been established at the time of this writing, but will be established as the configurations of the plants progress.

\subsubsection{Component Test Capability}

The NGNP Project Risk Management Plan has identified to-date a significant number of large scale tests that need to be completed on critical components to achieve the Technology Readiness Level necessary to install the components in the FOAK plant. Several studies have been done to develop the requirements for a facility to perform this testing and to identify existing or planned facilities in which this testing could be performed. The conclusions of these studies are that no complete facility exists or is planned in which these tests could be run. Several alternatives have been identified to complete these tests, (e.g., (1) do not perform large scale testing before installation in the plant; the plant becomes the test vehicle, (2) require the component or system supplier to perform the tests, (3) provide a new test capability - either in several facilities or in one consolidated facility - to perform the tests. The objective for this capability has been expanded as well to not only support the NGNP Project but also to support all Advanced Reactor testing requirements. A mission needs statement has been submitted for CD-0 for this capability along with identification of these alternatives and criteria for evaluation of the alternatives. This effort was separated from the NGNP Project in FY 2009. The following action is required in FY 2010 to support the NGNP Project:

- CD-0 approval,

- Evaluation of alternatives completed and a path forward selected,

- Conceptual design completed on the selected path forward, 
- $\quad$ CD-1 approved and

- Initiation of final design and construction.

\subsubsection{Hydrogen Processes}

As noted in a prior section, the ability to supply hydrogen along with steam, electricity and high temperature heat increases the value of applying the HTGR technology to many of the potential endusers, (e.g., petro-chemical plants, fertilizer producers). The development of the hydrogen processes was being supported under the Nuclear Hydrogen Initiative (NHI) until it was cancelled in FY 2009. Upon cancellation of the NHI the scope and funding of that program was transferred to the NGNP Project. This is an important developmental area that should continue to be fully funded under the Project through demonstration of the process in the Component Test Capability.

\subsubsection{Improving Cost and Schedule Estimate Confidence Levels}

The current cost and schedule estimates for completing the NGNP Project and for design, construction and operating an HTGR plant in a commercial application are based primarily on information developed in the FY 2007 Pre-Conceptual Design Work. This information was developed for the larger scale pebble bed and prismatic block design reactors (e.g., $500 \mathrm{MWt}$ to $600 \mathrm{MWt}$ ) operating at $900^{\circ} \mathrm{C}$ to $950^{\circ} \mathrm{C}$ reactor outlet temperature in a configuration that included primary to secondary gas loop intermediate heat exchangers supplying hot gas to steam generators, turbines that produced electricity, and hydrogen production facilities. As noted, this information has been revised as the trade studies on variations from these operating conditions and configuration were completed in FY 2008 and FY 2009, (e.g., evaluation of end-user needs which resulted in a reduction in reactor outlet temperature to the range $750^{\circ} \mathrm{C}$ to $800^{\circ} \mathrm{C}$ ). Data on prior work to characterize smaller prismatic block reactor designs (e.g., the MHTGR developed by DOE with General Atomics in the later 1980s) have also been used to examine the effect of lower reactor power, (e.g., $350 \mathrm{MWt}$ versus $600 \mathrm{MWt}$ ). The pre-conceptual status of this information, however, results in only a 50\% confidence in the estimated cost and schedule for the NGNP Project. More design effort is required to improve confidence in these estimates.

As noted in prior sections, in the latter part of FY 2009 the nuclear system suppliers reported that the plant that appears to offer the best short term solution to meeting potential end-user energy needs is one that operates in the range of $750^{\circ} \mathrm{C}$ to $800^{\circ} \mathrm{C}$ at a power level of $200 \mathrm{MWt}$ to $250 \mathrm{MWt}$ for the pebble bed reactor and $350 \mathrm{MWt}$ to $600 \mathrm{MWt}$ for the prismatic block reactor. The configuration of the plant includes only a steam generator in the primary loop feeding a steam turbine generator supplying electricity and steam (e.g., from extraction on the turbine) to a commercial facility. This has been recommended as the FOAK plant for the NGNP Project. However, the Project has been proscribed from completing any work on these designs and, accordingly, there has been no development of costs and schedules for completing the designs, constructing, testing and operating these plants. The conceptual designs for these plant operating conditions and configurations need to be completed to improve the confidence level in the estimates of the cost and the schedule for completing the NGNP Project. This effort should also develop the required funding profile by task for each of these plants.

\subsubsection{Product Contamination}

The application of the HTGR for supplying energy to commercial and industrial facilities is an extension of the use of nuclear power for more than the generation of electricity. In these commercial applications the HTGR may be supplying energy, (e.g., in the form of steam, hot gas) directly to a process that either produces raw materials for fabrication of products, (e.g., ethylene used in plastics) or a product itself, (e.g., hydrogen that could be used in many different applications). Depending on the application the supplied energy will have to meet specifications on contaminants. The existing specifications for 
these applications do not in general cover the potential contaminants, (e.g., radionuclides and other derivatives, (e.g., tritium)) that are produced in a nuclear reactor based plant. The investigations in this area by the Project have concentrated on characterizing the constituents and quantities of potential waste effluents from the plant. Work has been initiated to identify potential contaminants that could be transmitted into the energy supply streams from the plant to the process, (e.g., steam and hot gas), the potential quantities that could be produced, the mechanisms for transmission and the barriers that can be provided to eliminate or reduce the transmission to the energy streams.

This work has developed a tritium permeation code that can be configured for specific conditions and applications. The code will be validated in FY 2010 \& FY 2011 using tritium mass balance data from the Japanese High Temperature Test Reactor . Similar work is required for the other radionuclides.

It will also be necessary to work with the potential end users to understand the uses of the energy, the possibility for contamination of products from the process and the limits on contamination from potential constituents from the reactor plant.

\subsubsection{Co-location with Process}

Commercial application of the HTGR technology may require close co-location of the HTGR plant with the process, (e.g., within or just outside the process facility fence). This may be required to reduce losses in the energy supplied via steam and hot gas. There are several factors that have both design and licensing (NRC, state and local) impact that need to be addressed during conceptual design and in the discussions with potential end users including:

- Coordination of local, state, federal, (e.g., EPA) \& NRC regulations

- Access control \& security authority and overlapping jurisdiction

- Emergency Procedure interactions, authority and overlapping jurisdiction

- Potential interactive hazards, (e.g., from the facility to the HTGR Plant and from the HTGR plant to the facility)

- Construction on brownfield / contaminated site conditions

- Energy supply interfaces and energy demand characteristics, (e.g., transients, trip, average values)

A broad range of potential end uses and sites will need to be evaluated to establish bounding conditions to inform design and licensing of the reference plants.

\subsubsection{Multiple Modules}

A typical plant using the HTGR technology will include several HTGR modules potentially of varying capacity and configuration. They will typically be installed staggered in time, but when all are complete will operate in combination to satisfy process demand cycles and process availability requirements, (e.g., excess HTGR plant capacity may be provided to ensure that availability requirements are met when a module is down for maintenance or refueling). This arrangement is different from the current use of nuclear plants for electricity production. In a typical current application of a LWR in the US a single reactor plant will supply a steam turbine generator attached to the grid. Each plant will be controlled from a single control area. In the case where there is more than one reactor on a site the control areas may be contained in either a single or multiple control rooms but the control panel areas are separated in either case. The configurations and operation of the HTGR plant multiple modules will be more consolidated than is typical in multiple light water reactor plants. The following factors need to be considered in the design and licensing for the HTGR Plants: 
- Design of the consolidated control room for all the modules in the plant with efficiency and human factors considerations

- Number of operators required for monitoring, control and inspection of the plant

- Use of common support systems, (e.g., refueling systems used in prismatic block designs)

- Common fluctuating loads on the multiple modules

- Operating completed modules while constructing / refueling / modifying other modules in the plant

- How multiple modules will be accounted for in establishing plant source terms under licensing basis events.

\subsubsection{Integration with Industrial Processes}

It is important that the design of the HTGR plant be informed by the needs of potential end users with as wide a brush as feasible. Efforts to date have concentrated on co-generation applications supplying steam and electricity to a co-located process facility, such as a petro-chemical plant or refinery. The needs of the Alberta Oil Sands and to a lesser extent the needs for oil shale extraction have been explored and characterized. Work has also been initiated on the integration of the HTGR technology with refining processes, coal to synthetic fuels and ammonia and derivative products used in fertilizer production. Further work is required in all of these areas as well as others such as metallurgical coke production, petro-chemical processes such as ethylene \& styrene production, calcination of carbonates and phosphates, to clearly identify the design features required to meet the energy requirements and to be compatible with the codes, standards and regulatory requirements associated with the process and the HTGR plant. This work also needs to develop sufficient design, construction and operating cost and plant development and implementation schedules to develop economic \& business cases for these applications sufficient to support initial discussion with the end users. 


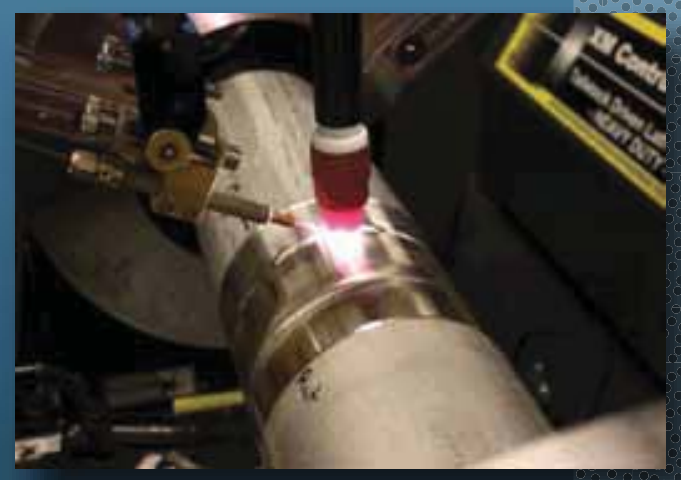




\section{Document Information}

Document ID: INL/EXT-09-17505 Revision ID: 0

Document Title/Description:

Next Generation Nuclear Plant Project 2009 Status

Report

Document Author/Creator:

Keith Perry

Document Owner:

Keith Perry

Project Number:

23843

Originating Organization: INL Sub-Project No: Date of Record: $\quad 05 / 12 / 10$ OR Date Range:

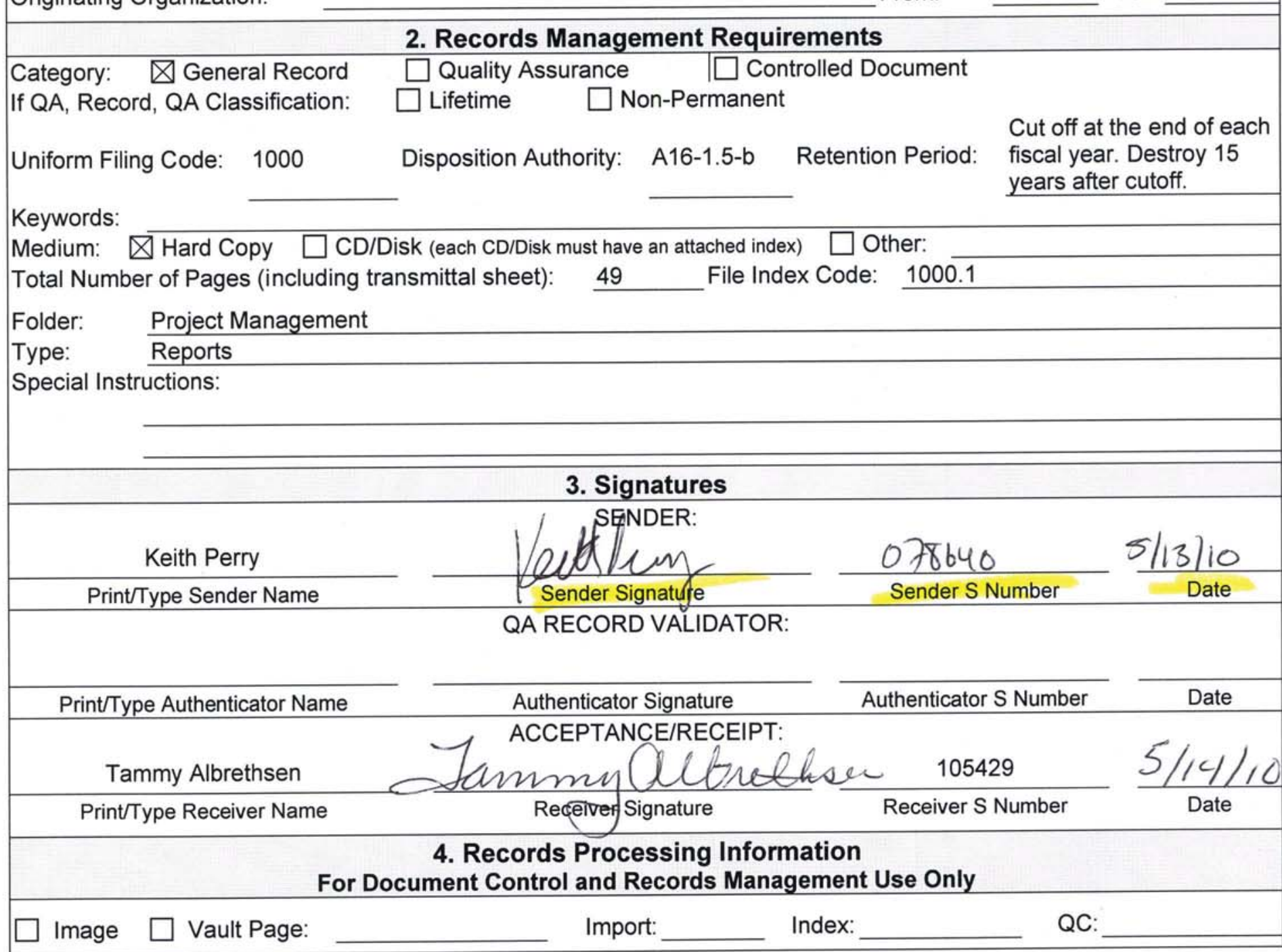

NOTE: This transmittal to be used in accordance with PLN-1485. Instructions for completion can be found on Form 435.77A. 